\title{
Modeling decadal variability of the Baltic Sea: 2. Role of freshwater inflow and large-scale atmospheric circulation for salinity
}

\author{
H. E. Markus Meier \\ Rossby Centre, Swedish Meteorological and Hydrological Institute, Norrköping, Sweden
}

Frank Kauker

Alfred Wegener Institute for Polar and Marine Research, Bremerhaven, Germany

Received 28 January 2003; revised 30 May 2003; accepted 2 September 2003; published 28 November 2003.

[1] Hindcast simulations for the period 1902-1998 have been performed using a threedimensional coupled ice-ocean model for the Baltic Sea. Daily sea level observations in Kattegat, monthly basin-wide discharge data, and reconstructed atmospheric surface data have been used to force the Baltic Sea model. The reconstruction utilizes a statistical model to calculate daily sea level pressure and monthly surface air temperature, dew point temperature, precipitation, and cloud cover fields. Sensitivity experiments have been performed to explore the impact of the freshwater and saltwater inflow variability on the salinity of the Baltic Sea. The decadal variability of the average salinity is explained partly by decadal volume variations of the accumulated freshwater inflow from river runoff and net precipitation and partly by decadal variations of the large-scale sea level pressure over Scandinavia. During the last century two exceptionally long stagnation periods are found, the 1920 s to 1930 s and the 1980 s to 1990 s. During these periods, precipitation, runoff, and westerly winds were stronger, and salt transports into the Baltic were smaller than normal. As the response timescale on freshwater forcing of the Baltic Sea is about 35 years, seasonal and year-to-year changes of the freshwater inflow are too short to affect the average salinity significantly. We found that the impact of river regulation, which changes the discharge seasonality, is negligible. INDEX TERMS: 4215 Oceanography: General: Climate and interannual variability (3309); 4243 Oceanography: General: Marginal and semienclosed seas; 4255 Oceanography: General: Numerical modeling; KEYWORDS: Baltic Sea, climate variability, modeling, major Baltic inflows, stagnation period, freshwater inflow

Citation: Meier, H. E. M., and F. Kauker, Modeling decadal variability of the Baltic Sea: 2. Role of freshwater inflow and large-scale atmospheric circulation for salinity, J. Geophys. Res., 108(C11), 3368, doi:10.1029/2003JC001799, 2003.

\section{Introduction}

[2] The hydrography of the Baltic Sea depends on the water exchange with the world ocean which is restricted by the narrows and sills of the Danish Straits (Figure 1) and on river runoff into the Baltic. In the long-term mean, highsaline water from the Kattegat enters the Baltic proper and low-saline water leaves the Baltic because of the freshwater surplus.

[3] The bottom water in the deep subbasins is ventilated mainly by large perturbations, so-called major Baltic saltwater inflows [Matthäus and Franck, 1992; Fischer and Matthäus, 1996]. These events occur randomly during the winter half year at intervals of one to several years. They are most probable between November to January, but they occur also in autumn and spring. Major saltwater inflows are very likely to be forced by a sequence of easterly winds lasting for 20-30 days followed by strong to very strong

Copyright 2003 by the American Geophysical Union. 0148-0227/03/2003JC001799\$09.00 westerly winds of similar duration [Lass and Matthäus, 1996]. Since the mid-1970s, the frequency and intensity of major inflows has decreased. They were completely absent between February 1983 and January 1993. During this phase a significant depletion of salt and oxygen occurred, and an increase of hydrogen sulphide were observed in the deep layer of the Gotland Basin. A major saltwater inflow in January 1993 terminated this exceptionally long stagnation period.

[4] Different mechanisms for the decreased frequency of major inflows are discussed in the literature. It has been argued that the lack of major inflows was due to changes in the wind field over the North Sea and the Baltic Sea [Lass and Matthäus, 1996]. Recently, it was claimed that variations in river runoff have a greater impact on the occurrence of major inflows than hitherto supposed [Schinke and Matthäus, 1998]. Matthäus and Schinke [1999] suggested that increased winter runoff (from September to March) reduce the probability of major Baltic inflows. Increased zonal circulation with intensified precipitation and increased river runoff and the anthropogenic impact on the freshwater 


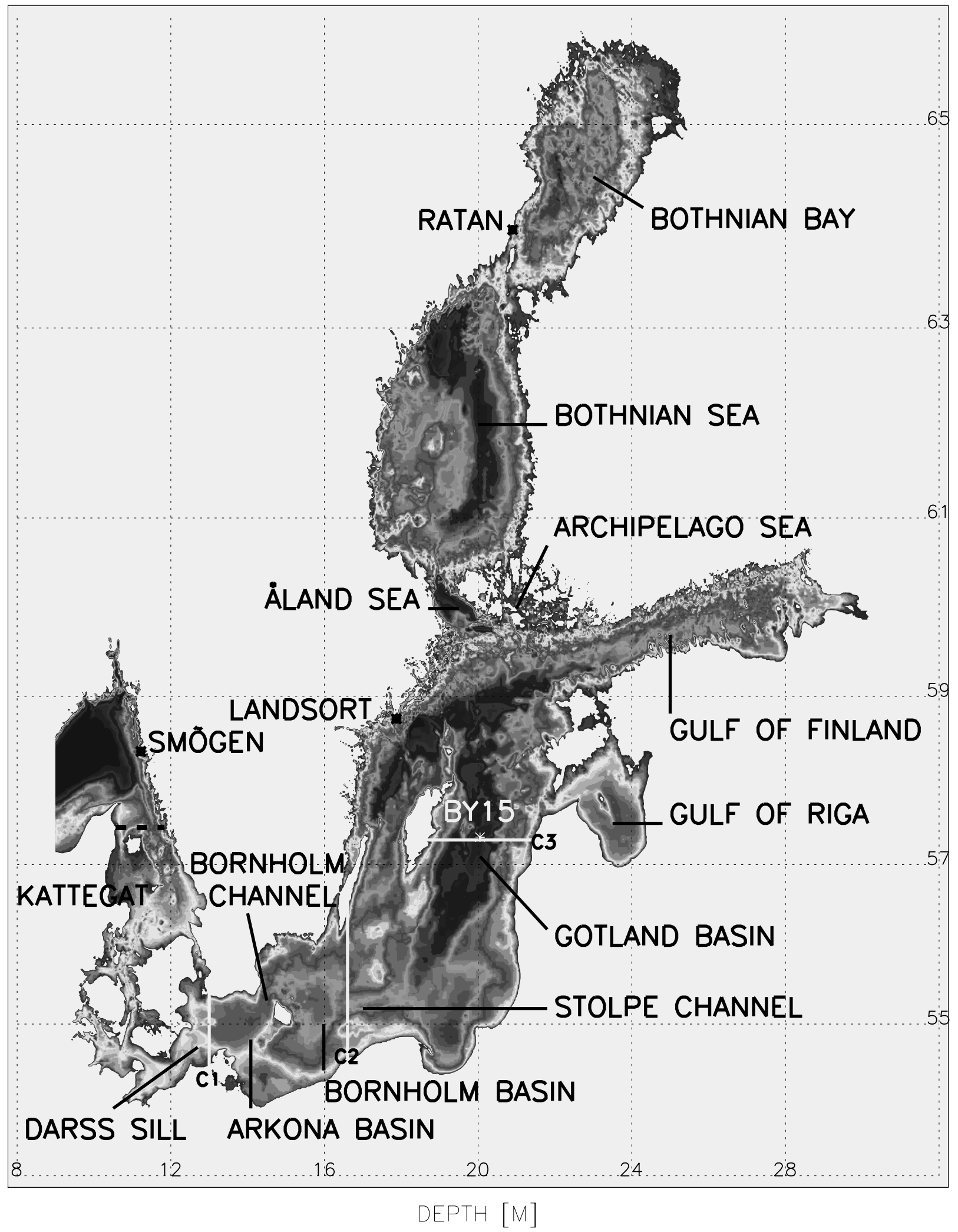

$0 \begin{array}{llllllllllllllllllllll} & 6 & 9 & 12 & 15 & 18 & 21 & 24 & 27 & 30 & 36 & 42 & 48 & 54 & 60 & 66 & 72 & 78 & 84 & 90 & 96 & 102114126150175200250\end{array}$

Figure 1. Bottom topography of the Baltic Sea including Kattegat and Skagerrak (data from Seifert and Kayser [1995]). The domain of the Rossby Centre Ocean model (RCO) is limited with open boundaries in the northern Kattegat (dashed line). Selected monitoring positions and cross sections (C1 to $\mathrm{C} 3$, white lines) are depicted additionally. See color version of this figure at back of this issue. 
cycle by seasonal redistribution of runoff due to river regulation have been mentioned. Zorita and Laine [2000] could show that a stronger meridional sea level pressure (SLP) gradient over the North Atlantic, and therefore stronger westerly winds, causes positive rainfall anomalies in the Baltic Sea catchment area. Consequently, increased runoff reduces salinities at all depths and at all stations included in their statistical analysis based on monthly values.

[5] 100 years of hydrographic data have been analyzed with focus on the freshwater budget by Winsor et al. [2001]. They found that variations of the mean salinity reflect the accumulated changes of river runoff. Winsor et al. [2001] assumed that there must be a strong positive feedback between the freshwater content of the Baltic Sea and the return of freshwater equivalents with the inflows. The responsible mechanism behind the feedback is supposed to be a very effective mixing in the Danish Straits [Rodhe and Winsor, 2002].

[6] The sensitivity of Baltic Sea climate has been investigated earlier using process-oriented models [e.g., Stigebrandt, 1983; Omstedt and Nyberg, 1996; Omstedt and Axell, 1998; Gustafsson, 2000]. Gustafsson [2000] found that the deepwater renewal is obstructed during years with high freshwater supply even if the sea level forcing is favorable to a major inflow. Meier et al. [2003] performed a series of process studies of the inflow period 1992/1993 using a high-resolution primitive equation model for the Baltic Sea. Their results for the impact of river runoff were in agreement with those by Gustafsson [2000]. Natural interannual runoff variations modify saltwater inflows into the Bornholm Basin significantly.

[7] In this study, we present sensitivity studies for the period 1902-1998 using a three-dimensional (3-D) coupled ice-ocean model for the Baltic Sea. The atmospheric forcing for this period has been reconstructed utilizing a statistical model and is described in detail in an accompanied paper [Kauker and Meier, 2003]. The study aims to answer the following questions.

[8] 1. Is the quality of the reconstructed atmospheric data set sufficient to model climate and decadal variability of the Baltic Sea?

[9] 2. From coarse resolution $z$ coordinate models it is known that they underestimate gravity driven dense bottom flows if the bottom boundary layer is not resolved explicitly [see Meier et al., 2003]. Is the performance of our 3-D general circulation model good enough to perform 100-year simulations of the Baltic Sea?

[10] 3. What is the reason for the decreased frequency and intensity of major saltwater inflows since the mid1970s? In general, what is the influence of saltwater and freshwater inflows on decadal variability of salinity in the Baltic Sea?

[11] The paper is organized as follows: In the second section, the model is presented briefly. The atmospheric forcing, runoff data, sea level data at the open boundary, and initial conditions are described in the third section. In the fourth section, model results of sea level, sea ice cover, saltwater inflow, salinity, and volume and salt transports are validated by comparison with observations. In section 5, results of the sensitivity studies are shown. The decadal variability of volume and salt fluxes at three cross sections is analyzed in section 6. The paper ends with a discussion and conclusions.

\section{Model Description}

[12] The Rossby Centre Ocean model (RCO) utilizes the code of the Ocean Circulation Climate Advanced Modeling (OCCAM) project of the Bryan-Cox-Semtner primitive equation ocean model with an explicit free surface $[\mathrm{Webb}$ et al., 1997]. Open boundary conditions according to Stevens [1990] are implemented in the northern Kattegat (Figure 1). An improved turbulence scheme is used [Meier, 2001]. The ocean model in RCO is coupled with a Hiblertype [Hibler, 1979] two-level (open water and ice) dynamicthermodynamic sea ice model.

[13] The model depths are based on realistic bottom topography data [Seifert and Kayser, 1995] (Figure 1). RCO uses 41 levels with layer thicknesses from $3 \mathrm{~m}$ close to the surface to $12 \mathrm{~m}$ near the bottom. The maximum depth in RCO is $250 \mathrm{~m}$. For the long-term simulations described here, a horizontal resolution of 6 nautical miles is used. Standard bulk formulae are utilized [Meier, 2002a]. Wind speeds in $10 \mathrm{~m}$ height are calculated from geostrophic winds according to Bumke et al. [1998]. As the SLP fields are reconstructed only as daily mean values, the energy flux to inertial motions is underestimated [D'Asaro, 1985]. Therefore the reduction coefficient is increased by $11 \%$. The latter factor has been estimated comparing frequency distributions of reconstructed wind speeds and observations at the station Landsort (Figure 1). At this station, a long record of observations exists since 1961 (see next section). It is assumed that these data represent sea wind with minor disturbance from land. For a more detailed model description of RCO the reader is referred to Meier et al. [1999], Meier [2001], and Meier et al. [2003].

\section{Forcing Data and Initial Conditions}

\subsection{Atmospheric Forcing}

[14] The atmospheric forcing has been reconstructed using a statistical model based on a Redundancy Analysis [Kauker and Meier, 2003]. To be able to simulate major saltwater inflows with a timescale of 20 days SLP has been predicted for every day. However, the seasonal water and energy cycles are sufficiently reproduced using only monthly surface air temperature, dew point temperature, precipitation, and cloudiness. Predictor variables are 100 years of SLP at 18 locations, 100 years of sea surface air temperature on a $5^{\circ} \times 5^{\circ}$ regular horizontal grid, and 100 years of precipitation on a $2.5^{\circ} \times 3.75^{\circ}$ regular grid. The second input to the statistical model is a gridded $1^{\circ} \times 1^{\circ}$ atmospheric data set based on synoptic stations, which is available for the period 1970-1998. Spatial patterns, the redundancy modes, are selected by maximizing predictand variance during the "learning" period 1980-1998. The remainder period 1970-1979 is used for validation. For details the reader is referred to Kauker and Meier [2003].

[15] In section 5, it will be shown that the low-frequency variability of the zonal surface wind has a significant impact on the decadal variability of salinity in the Baltic Sea. In Figure 2 the $10 \mathrm{~m}$ wind calculated from the reconstructed 


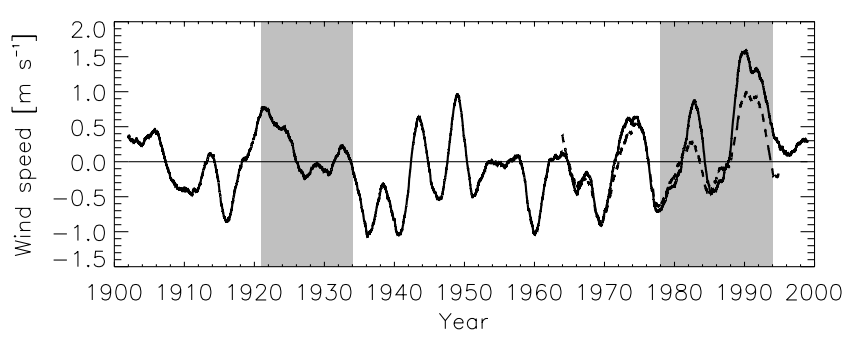

Figure 2. The 4-year running mean zonal wind speed anomalies (in $\mathrm{m} \mathrm{s}^{-1}$ ) at Landsort (see Figure 1): reconstruction (solid) and observations (dashed). The shaded ranges indicate periods with a positive anomaly of the 4-year running mean runoff related to stagnation phases (see Figure 3).

SLP is compared to wind observations at Landsort. For the period 1902-1998 the total mean reconstructed wind speed at Landsort amounts to $1.56 \mathrm{~m} \mathrm{~s}^{-1}$ with an angle of $272^{\circ}$ according to the wind rose $\left(0^{\circ}\right.$ is wind from the North). Similar values are found for the period 1964-1998. During this period the mean reconstructed and observed wind speeds at Landsort are in very good agreement with values of $1.72 \mathrm{~m} \mathrm{~s}^{-1}$ and $1.87 \mathrm{~m} \mathrm{~s}^{-1}$, respectively. The variability for periods larger than four years is well reproduced by the reconstruction (Figure 2). However, the mean values of the angle differ somewhat with values of $268^{\circ}$ (reconstruction) and $241^{\circ}$ (observation). This might be caused by special orographic conditions at Landsort which are not captured by the reconstruction.

\subsection{River Runoff}

[16] River runoff is considered in RCO by means of the 29 most important rivers. For them, monthly mean discharges for the period 1902-1998 have been calculated from three data sources: (1) river runoff data for the period 1950-1998 from the Baltic Sea Experiment Hydrological Data Centre (BHDC) at the Swedish Meteorological and Hydrological Institute (SMHI) (The monthly data do not only represent the inflow by major rivers, but the runoff through coastal segments including estimated smaller runoff ways [Bergström and Carlsson, 1994]); (2) subbasin river discharge for the period 1921-1975 presented by Mikulski [1986] (17 rivers representative for the selected drainage areas are considered); and (3) total discharge of the period 1901-1990 for the entire Baltic catchment area calculated by Cyberski and Wroblewski [2000].

[17] The database of the BHDC consists of data from some 200 river flow stations, most of them near the mouths of the rivers [Bergström and Carlsson, 1994]. The catchment areas of these stations represent $86 \%$ of the total drainage basin. Bergström and Carlsson [1994] estimated the error of the total monthly runoff from Sweden and Denmark to be $8-17 \%$ and $5-15 \%$, respectively. Although the calculations of total runoff for the other countries are based on only a few large rivers, the uncertainty is roughly estimated to be of the same order of magnitude. Mikulski's estimates are based on a sample of 17 rivers for the period 1921-1975 [Mikulski, 1986]. The catchment of these rivers represent $63 \%$ of the total drainage basin. Bergström and Carlsson [1994] have shown that the database of the BHDC and Mikulski's [1986] data agree fairly well for the overlap period 1950-1975. The greatest differences were found in the estimates for the Bothnian Sea and Baltic proper of maximum $20 \%$ for the annual mean runoff. Before 1921 the runoff data are less reliable. Complete information is available for only 12 rivers [Cyberski and Wroblewski, 2000]. Runoff of the other five rivers also used in the study by Mikulski [1986] were reconstructed by Cyberski and Wroblewski [2000] using statistical methods based on 70 -year data series from the 17 rivers $(1921-1990)$. For our study, only the total monthly runoff data for the entire Baltic Sea were available.

[18] The runoff data are produced in two steps. First, climatological mean ratios between runoff of the selected 29 rivers and the corresponding subbasin discharges are calculated for the period 1950-1998 using the data by Bergström and Carlsson [1994]. In addition, the ratios between individual river runoff and the whole Baltic Sea discharge are calculated. Second, monthly subbasin discharges are calculated for the period 1921-1998 and missing values have been replaced by results of the HBV model, a large-scale hydrological model by Graham [1999]. Finally, monthly river discharges for the period 1902-1998 are reconstructed utilizing either monthly basin discharges for the period $1902-1920$ or monthly subbasin discharges for the period 1921-1998. The available higher spatial resolution for most of the period 1950-1998 has not been utilized for homogeneity reasons. The results are shown in Figure 3. For the period 1902-1998 the total mean river runoff to the Baltic Sea without Kattegat amounts to $14,085 \mathrm{~m}^{3} \mathrm{~s}^{-1}$. There is no significant trend in the annual mean runoff.

[19] However, the seasonal cycle has changed during the past century (Figures $3 \mathrm{~b}$ and 4 ). Especially, the winter mean runoff for January through March has increased significantly since the 1970s. Correspondingly, summer mean runoff for June through August has decreased. It is believed that this change in the seasonality of river runoff is caused mainly by river regulation. Since the 1970 s many dams have been built in Sweden and Finland.

[20] The linear correlation between reconstructed annual mean precipitation over the Baltic Sea (not shown) and annual mean river runoff (Figure 3) amounts to $r=0.54$. The corresponding correlation based on 4-year annual mean values is 0.82. Thus the precipitation over the Baltic Sea and the river runoff of the Baltic catchment area are highly coherent on decadal timescale. (In this study "decadal variability" is used synonymously for all variations with periods larger than 4 years.)

\subsection{Sea Level in Kattegat}

[21] At the open boundary in the Kattegat daily sea level data are prescribed from the Swedish tide gauges in Strömstad (1902-1910) and Smögen (1910-1998; see Figure 1). Missing values have been replaced by linear interpolation. The linear trends due to land uplift are subtracted from the data following Ekman [1996] (3.53 $\mathrm{mm} \mathrm{yr}^{-1}$ for Strömstad and $2.99 \mathrm{~mm} \mathrm{yr}^{-1}$ for Smögen assuming a custatic sea level rise of $1 \mathrm{~mm} \mathrm{yr}^{-1}$ ). These trends are supposed to be related to land uplift only. The decrease of apparent postglacial land uplift (uplift relative to sea level) since 1885, possibly caused by thermal expansion of the world ocean and melting of mountain glaciers [Ekman, 1999], and decade 


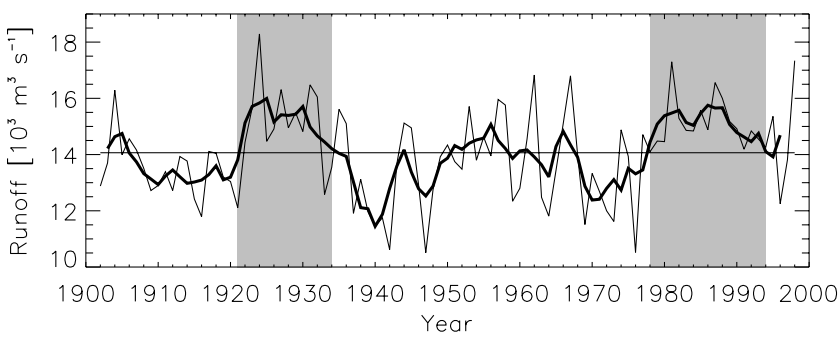

b

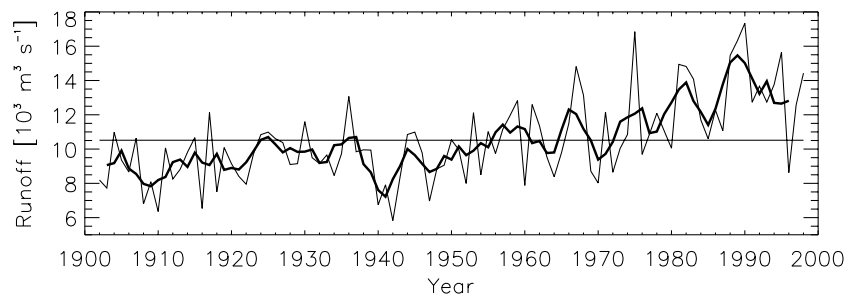

Figure 3. (a) Annual mean and (b) winter mean (January through March) river runoff (in $10^{3} \mathrm{~m}^{3} \mathrm{~s}^{-1}$ ) to the Baltic Sea without Kattegat (thin line). In addition, the 4-year running mean (thick line) and the total mean for the period 1902-1998 (horizontal line) are shown. The shaded ranges in Figure $3 \mathrm{a}$ indicate periods with positive anomalous 4-year running mean runoff, which are related to stagnation phases.

long trends of the atmospheric forcing itself are still included in the Kattegat sea level data.

[22] In addition, the mean values of the time records have been subtracted and replaced by the values of the Nordic height system 1960 (NH60), a geodetic solution published by Ekman and Mäkinen [1996]. As the open boundary approximately follows a line between Frederikshavn in Denmark and Ringhals in Sweden the mean sea levels in the model have been chosen to be $-11.1 \mathrm{~cm}$ at Frederikshavn and $-1.4 \mathrm{~cm}$ at Ringhals according to NH60. Between these two locations the mean sea level at the open boundary is interpolated linearly.

\subsection{Initial Conditions}

[23] Profiles from the Marine Data Centre of the International Council for the Exploration of the Sea (ICES) have been selected to compile initial conditions for temperature and salinity on 1 November 1902. Thereby, the Baltic Sea has been divided into 14 subbasins. The borders have been chosen according to topographic features. The hydrography of each subbasin is assumed to be homogeneous and is represented by one profile casted at the deepest location. Initial sea level and velocities have been set to zero.

\section{Model Validation}

[24] Hereinafter, the standard experiment described in section 3 is referred to as H1 (Table 1).

\subsection{Sea Level}

[25] The tide gauge at Landsort (see Figure 1) is located close to the nodal line of the first seiche of the system between the western Baltic and the Gulf of Finland
[Neumann, 1941]. Thus the sea level at Landsort is a good measure of the Baltic Sea volume [e.g., Janssen, 2002]. In Figure 5 the agreement between observed and simulated sea levels with periods longer than 20 days indicates that those transports through the Danish Straits are simulated correctly which are relevant for major Baltic inflows [Matthäus and Franck, 1992]. In Figure 5 the strong signal of anomalous high sea level in December 1951 indicates a major Baltic inflow.

[26] The errors of the simulated sea level at two stations with long records of observations are summarized in Table 2. At Landsort a considerable amount of variance $(64 \%)$ for periods longer than 4 days are described by the model. However, for Ratan we found a larger RMS error and smaller explained variance because the simulated sea levels in the Bothnian Bay for periods longer than about 20 days are overestimated. An additional model experiment performed without increased wind speed showed improved performance (Table 2). Consequently, our approach to improve the lack of mixing with a constantly increased reduction coefficient is too simple. The reconstructed wind fields without correction underestimate only the variability on very short timescales ( $<2$ days) but show reasonable results for the longer periods.

\subsection{Sea Ice}

[27] Data of the annual maximum ice extent of the Baltic Sea (MIB) are collected by the Finnish Institute of Marine Research (FIMR). Original data by Jurva [1944] were destroyed in World War II. However, the time series was reconstructed by Palosuo [1953] and subsequently extended by Seinä and Palosuo [1993]. The variability of MIB is simulated in good agreement with the observations but the ice cover is somewhat overestimated (Figure 6). During $1903-1998,71 \%$ of the observed variance is described by the simulated MIB (Table 3).

[28] The error increases back in time in two steps, i.e., around 1966 and 1926 (Figure 6 and Table 3). Interestingly, the two steps with decreasing MIB error coincide with increases of intensity and areal coverage of available ice observations.

[29] 1. In the late 1960 s the activity of aircraft ice reconnaissance was increased and first satellite observations became available.

[30] 2. On 11 February 1927 the Finnish merchant vessels were ordered by the Finnish Government to keep on-track sea ice diaries and to deliver those data to the Finnish Institute of Marine Research [Granqvist, 1928]. Hourly data

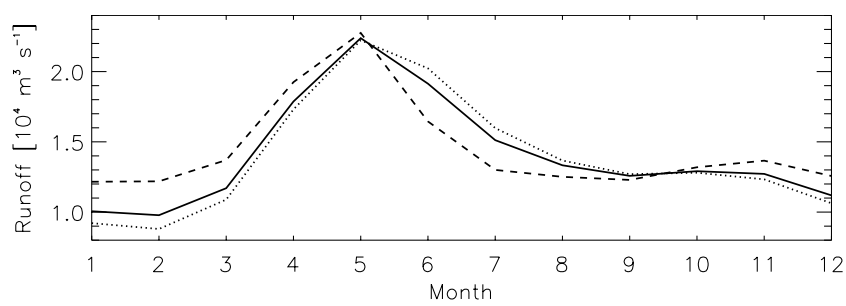

Figure 4. Climatological monthly mean river runoff (in $10^{4} \mathrm{~m}^{3} \mathrm{~s}^{-1}$ ) to the Baltic Sea without Kattegat for the periods 1902-1998 (solid line), 1902-1970 (dotted line), and 1971-1998 (dashed line). 
Table 1. RCO Experiments Analyzed in This Study ${ }^{\mathrm{a}}$

\begin{tabular}{|c|c|c|c|c|c|}
\hline Run & Period & Atmospheric Forcing & River Runoff & Sea Level Kattegat & Reference \\
\hline \multicolumn{6}{|c|}{ Standard Experiments } \\
\hline H1 & $1902-1998$ & stat. model (1d) & observed basins & observed (1d) & 4 \\
\hline $\mathrm{H} 2$ & $1980-1993$ & SMHI (3h) & observed rivers & observed (1h) & $4.2,4.4$ \\
\hline \multicolumn{6}{|c|}{ Sensitivity Freshwater Forcing } \\
\hline F1 & $1902-1998$ & $\begin{array}{l}\text { stat. model (1d), but climatol. } \\
\text { monthly mean precipitation } 1902-1970\end{array}$ & climatol. monthly mean runoff $1902-1970$ & observed (1d) & 5.1 \\
\hline $\mathrm{F} 2$ & $1942-1998$ & stat. model (1d) & $\begin{array}{l}\text { climatol. monthly mean runoff } 1902-1970 \\
\text { and interannual variability } 1942-1998\end{array}$ & observed (1d) & 5.1 \\
\hline A1 & $1902-1998$ & $\begin{array}{l}\text { Sensitivity } \\
\text { stat. model (1d), but climatol. } \\
\text { monthly mean precipitation } 1902-1970, \\
\text { 4-year high-pass-filtered SLP }\end{array}$ & $\begin{array}{l}\text { tmospheric Forcing } \\
\text { climatol. monthly mean runoff 1902-1970 }\end{array}$ & observed (1d) & 5.2 \\
\hline SI & $1902-1998$ & $\begin{array}{l}\text { Stat. model (1d), but air temp. } \\
\text { from 1941/1942 }\end{array}$ & $\begin{array}{l}\text { tivity Sea Ice } \\
\text { observed basins }\end{array}$ & observed (1d) & 5.3 \\
\hline $\mathrm{SL}$ & $1902-1998$ & Sensitivity & $\begin{array}{l}\text { Kattegat Sea Level } \\
\text { observed basins }\end{array}$ & 4-year high- pass filtered & 5.4 \\
\hline
\end{tabular}

${ }^{\mathrm{a}}$ In the last column, references to the corresponding sections of this study are listed. A statistical model is used to reconstruct daily sea level pressure and monthly surface air temperature, dew point temperature, precipitation, and cloud cover fields [Kauker and Meier, 2003]. Alternatively, 3 hourly observed atmospheric surface fields of the SMHI database are available since 1970.

of ice cover, ice severity, ice velocity, wind speed, etc., were recorded.

[31] Alternatively to a decreasing quality of the MIB observations back in time the quality of the input data to the statistical model (e.g., air temperature and precipitation) could have decreased. Also possible is that the statistical relationship between predictor and predictand variables estimated in the period 1980 to 1998 is not stationary. However, for SLP Kauker and Meier [2003] could show that the relationship is indeed stationary.

[32] For the period 1980-1993 the simulated total ice coverage with an ice concentration larger than 0.1 is compared with calibrated gridded weekly ice cover data from the Global Digital Sea Ice Data Bank of the USA National Ice Center [see Schrum et al., 2000]. The results of H1 are satisfactory but the biases are larger than in the hindcast experiment $\mathrm{H} 2$ with observed atmospheric forcing (Table 4).

\subsection{Major Baltic Inflows During 1902-1998}

[33] We have defined an event to be a major inflow if the simulated volume of high-saline water with $S \geq 17 \%$ o $\left(V_{17}\right)$ in the Arkona Basin is higher than $50 \mathrm{~km}^{3}$ during at least 6 consecutive days according to Matthäus and Franck [1992]. During the period 1902-1998 we found 180 major Baltic

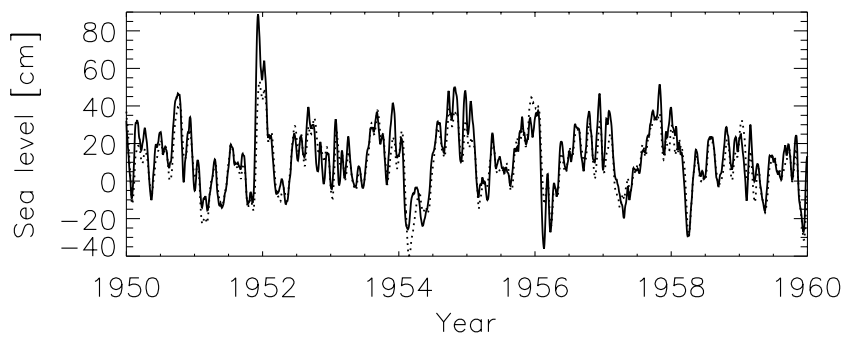

Figure 5. The 20-day running mean sea level (in $\mathrm{cm}$ ) at Landsort for the period 1950-1959. Solid line: model results. Dotted line: observations. inflows in $\mathrm{H} 1$ with a mean inflow volume of $V_{17}=105 \mathrm{~km}^{3}$ containing a mean salt amount of $M_{17}=2.3 \cdot 10^{12} \mathrm{~kg}$. Fischer and Matthäus [1996] analyzed 82 observed inflows for the period 1897-1976 excluding the two world wars. They calculated a mean inflow volume of $V_{17}=81 \mathrm{~km}^{3}$ and a mean salt amount of $M_{17}=1.6 \cdot 10^{12} \mathrm{~kg}$. Apparently, too many major Baltic inflows occur in the model with a too high mean salt amount. As the investigated periods are different and as the number of observed inflows is very likely underestimated (not all events have been detected), further investigations are still necessary to draw final conclusions. It might be that even the mean inflow volume in the model is overestimated compared to reality since weaker inflows are more difficult to detect; that is, observations should be biased toward stronger inflows. Using a semiempirical model, Gustafsson and Andersson [2001] identified 118 major Baltic inflows for the same period 1902-1998.

\subsection{Salinity}

[34] The minima during the 1930s and during the $1990 \mathrm{~s}$ of the lower-layer salinity in the eastern Gotland Basin (BY15; see Figure 1) and the pronounced maximum during the 1950s are simulated correctly (Figure 7). Even individual major saltwater inflows are reproduced well, for example, the events in November/December 1951 and in January 1993. The halocline depth is somewhat underestimated

Table 2. Model Errors of Twice Daily Sea Levels for Two Tide Gauges $^{\mathrm{a}}$

\begin{tabular}{ccccc}
\hline Station & $M E$ & $R M S E$ & $R$ & $V A R$ \\
\hline Landsort & 3.0 & 11.2 & 0.88 & 0.64 \\
& $(-0.6)$ & $(9.3)$ & $(0.88)$ & $(0.75)$ \\
Ratan & 3.9 & 15.7 & 0.83 & 0.55 \\
& $(-0.2)$ & $(13.6)$ & $(0.83)$ & $(0.66)$ \\
\hline
\end{tabular}

${ }^{\text {a }}$ See Figure 1. The values in parentheses are calculated using data from an additional model experiment performed without the increase of wind speed of $11 \%$. ME, mean error in $\mathrm{cm}$; RMSE, root mean square error in $\mathrm{cm}$; $R$, correlation coefficient; and $V A R$, explained variance. 


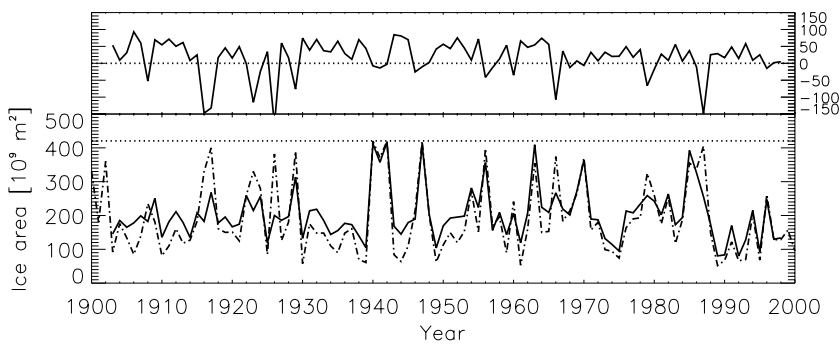

Figure 6. Annual maximum ice extent (in $10^{9} \mathrm{~m}^{2}$ ): observations (dash-dotted) and model results (solid). The differences between model results and observations are shown in the upper panel.

compared to observations and simulated decadal variations are smaller than observed.

[35] In Figure 8 the basin-wide averaged salinity of the Baltic Sea for the period 1902-1998 is shown. A comparison between the long standard experiment (H1) and a simulation with observed initial conditions from May 1980 (H2) shows that the average salinities of the period 1980-1993 are overestimated in the long simulation. We found a positive bias of $0.63 \%$ very likely caused by a model drift toward higher salinities during the first two decades of the century. After the first two decades the bias is stationary. As the halocline is too shallow, we assume that there is an initial imbalance. Consequently, during the first two decades increased saltwater inflow occurs until the system is in a new quasi steady state. However, when the bias is subtracted from the salinity record, the results of the long (H1) and short (H2) experiments are fitting quite well (Figure 8). The corrected mean salinity for the whole period 1902-1998 amounts to $7.36 \%$. Minimum and maximum values of the unfiltered record are $6.65 \%$ and $8.06 \%$, respectively. Our model results are confirmed by observations. The mean salinities calculated from a climatological data set of the Baltic Sea [Janssen et al., 1999] amount to $7.2-7.4 \%$ o for different months. In this data set observations from the period 1902-1996 are included. As more than $50 \%$ of the data are recorded after 1977 (for greater depths the data density maximum is shifted even more toward the stagnation period of the 1980s and 1990s), the total mean salinity of the whole period 1902-1996 is very likely somewhat underestimated by the data set.

\subsection{Freshwater Budget}

[36] For the period 1902-1998 the total mean net precipitation over the Baltic Sea in $\mathrm{H} 1$ amounts to $2,030 \mathrm{~m}^{3} \mathrm{~s}^{-1}$.

Table 3. Model Errors of Annual Maximum Ice Extent for the Whole Period 1903-1998, the Reconstruction Period 1903-1979, the Calibration Period 1980-1998, and for Periods With Possibly Variable Data Quality as Explained in the Text ${ }^{\mathrm{a}}$

\begin{tabular}{ccccc}
\hline Period & $M E$ & RMSE & $R$ & VAR \\
\hline $1903-1998$ & 16.8 & 55.2 & 0.87 & 0.71 \\
$1903-1979$ & 18.7 & 57.7 & 0.86 & 0.69 \\
$1980-1998$ & 9.2 & 43.9 & 0.92 & 0.82 \\
$1902-1926$ & 3.9 & 73.9 & 0.66 & 0.37 \\
$1927-1966$ & 29.1 & 52.8 & 0.94 & 0.79 \\
$1967-1998$ & 11.1 & 39.5 & 0.93 & 0.83 \\
\hline
\end{tabular}

${ }^{\mathrm{a}} M E$, mean error in $10^{9} \mathrm{~m}^{2} ; R M S E$, root mean square error in $10^{9} \mathrm{~m}^{2} ; R$, correlation coefficient; and $V A R$, explained variance.
Table 4. Model Errors of Weekly Mean Ice Cover for the Period $1980-1993^{\mathrm{a}}$

\begin{tabular}{lcccc}
\hline Run & $M E$ & $R M S E$ & $R$ & $V A R$ \\
\hline H1 & 19.1 & 37.0 & 0.91 & 0.69 \\
H2 & 12.6 & 27.4 & 0.94 & 0.83 \\
\hline
\end{tabular}

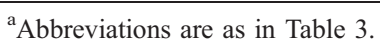

The inter-annual variability is large with a minimum of $-384 \mathrm{~m}^{3} \mathrm{~s}^{-1}$ (1975) and a maximum of $3,917 \mathrm{~m}^{3} \mathrm{~s}^{-1}$ (1981). Our mean value is somewhat higher than the result published by Rutgersson et al. [2002]. For the period 19011998 , they found a long-term average value of $1,152 \mathrm{~m}^{3} \mathrm{~s}^{-1}$ using a linear regression relationship between net precipitation, river runoff and MIB. On the basis of ice-ocean model results, Omstedt et al. [1997] and Meier and Döscher [2002] calculated a total mean net precipitation of $1,986 \mathrm{~m}^{3} \mathrm{~s}^{-1}$ and $1,843 \mathrm{~m}^{3} \mathrm{~s}^{-1}$ for the relatively wet periods $1981-1994$ and 1980-1993, respectively. (The results for net precipitation presented by Meier and Döscher [2002] were corrected because the surface area in the RCO model is overestimated by about $8.8 \%$. In the present study no correction has been applied.) Referring to an estimated bias of about $1,000 \mathrm{~m}^{3} \mathrm{~s}^{-1}$ [Rutgersson et al., 2002], our results are still within the estimated uncertainty margins.

[37] The linear correlation between annual mean net precipitation over the Baltic Sea and annual mean river runoff (Figure 3 ) amounts to $r=0.48$. The corresponding correlation based on 4-year annual mean values is 0.78 . These numbers show that the decadal variability of evaporation is relatively small. Consequently, also the net precipitation over the Baltic Sea and the river runoff of the Baltic catchment area are highly coherent on decadal timescale (see section 3.2 for precipitation).

[38] The freshwater content $F$ is calculated as

$$
F=\frac{1}{S_{\text {ref }}} \int_{x} \int_{y} \int_{z} \max \left(\left[S_{r e f}-S(x, y, z)\right], 0\right) d x d y d z
$$

where $S_{\text {ref }}$ is a reference salinity of the Kattegat deepwater $\left(S_{r e f}=33 \%\right)$, and $S(x, y, z)$ is the salinity of the current profile at the location $(x, y)$ and at the depth $z$. The total mean freshwater content for the period 1902-1998 amounts to $17,734 \mathrm{~km}^{3}$. This value is uncorrected; that is, the model drift toward higher salinities during the first 2 decades is not considered. With an average freshwater inflow of $16,115 \mathrm{~m}^{3} \mathrm{~s}^{-1}$ we found a freshwater residence time of 35 years. The simulated freshwater storage anomaly (Figure 9) is in good agreement with the results calculated from observations by Winsor et al. [2001, Figure 17]. We also found that the freshwater storage anomaly and the accumulated freshwater inflow are well correlated $(\mathrm{r}=0.80)$. (The calculations of the Baltic Sea freshwater content and mean salinity presented by Winsor et al. [2001] and Rodhe and Winsor [2002] were erroneous because of a fault in the hypsographic data used. However, this fault should not significantly affect the anomalies presented by Winsor et al. [2001].)

\subsection{Volume and Salt Fluxes}

[39] In $\mathrm{H} 1$ the mean deepwater volume flow in the Arkona Basin (C1; see Figure 1) amounts to $18,800 \mathrm{~m}^{3} \mathrm{~s}^{-1}$ 

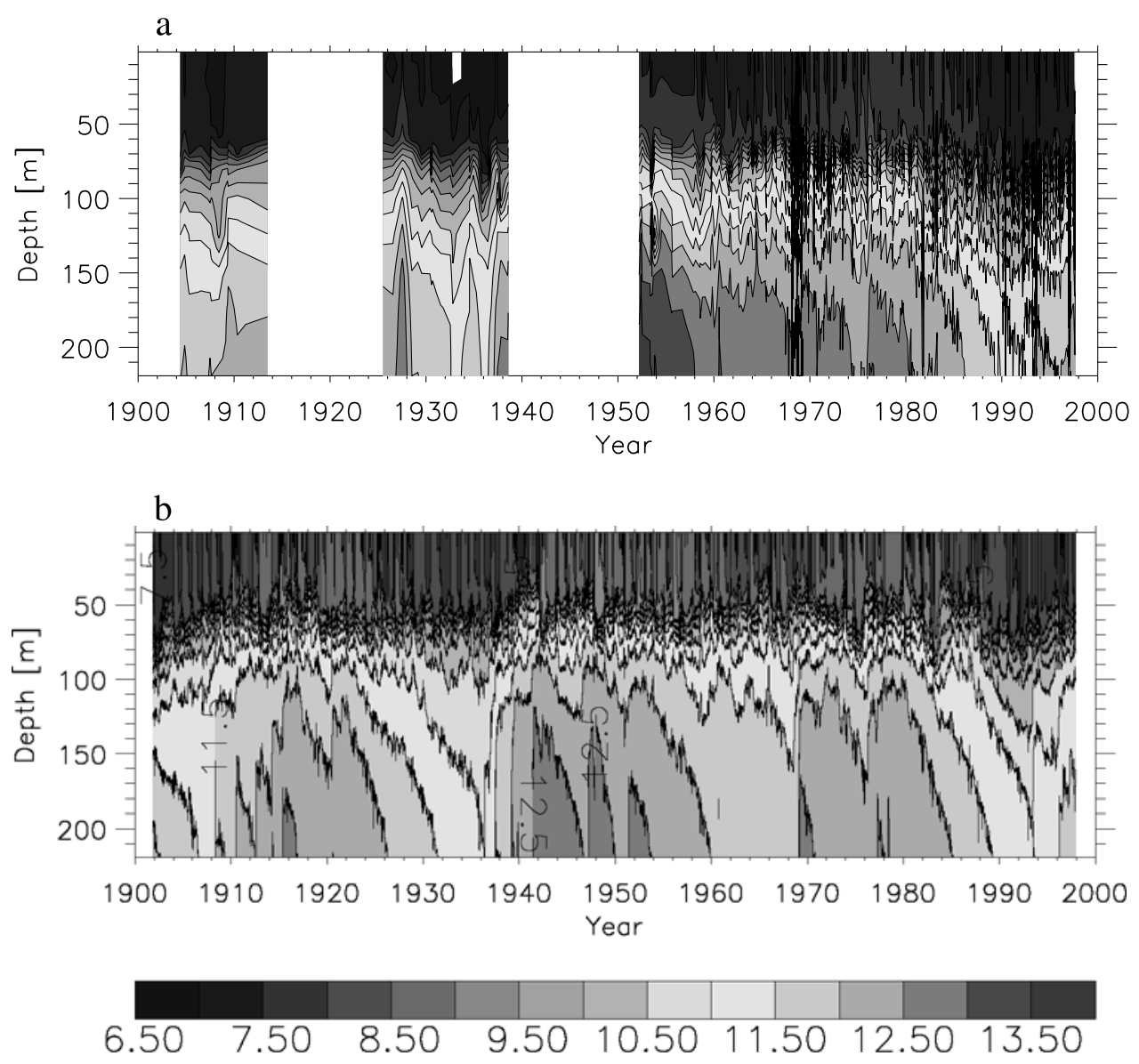

Figure 7. Salinity (in \%o) as function of time and depth in the eastern Gotland Basin (BY15): (a) observations and (b) model results. Observations are not available for periods covering the world wars. See color version of this figure at back of this issue.

for 1902-1998. On the basis of the assumption of geostrophic control Liljebladh and Stigebrandt [1996] and Gustafsson [2001] calculated a mean deepwater volume flow of $21,000 \mathrm{~m}^{3} \mathrm{~s}^{-1}$ from observations of the last century. In $\mathrm{H} 1$ the mean deepwater volume flow at Stolpe Channel (C2; see Figure 1) amounts to $30,100 \mathrm{~m}^{3} \mathrm{~s}^{-1}$ for $1902-$ 1998. Volume flows calculated from observations differ

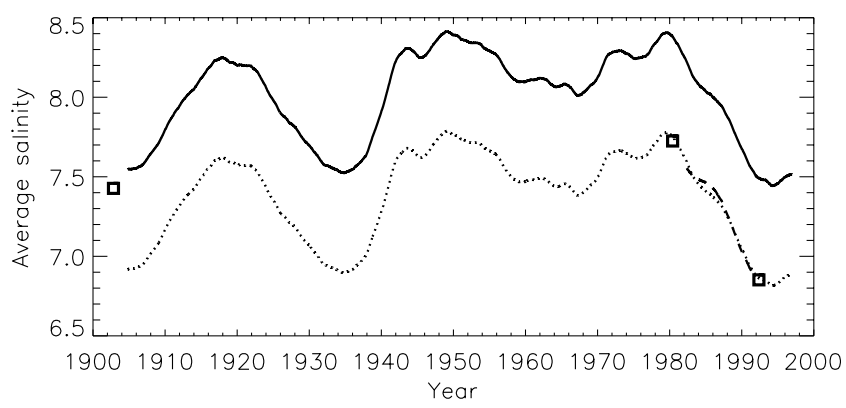

Figure 8. The 4-year running mean salinity in the Baltic Sea without Kattegat (in \%o). The solid and dotted curves denote the uncorrected and corrected model results of the standard experiment (H1), respectively. The dashed line denotes the short run H2. The squares denote mean salinities calculated from observations for November 1902, May 1980, and May 1992.

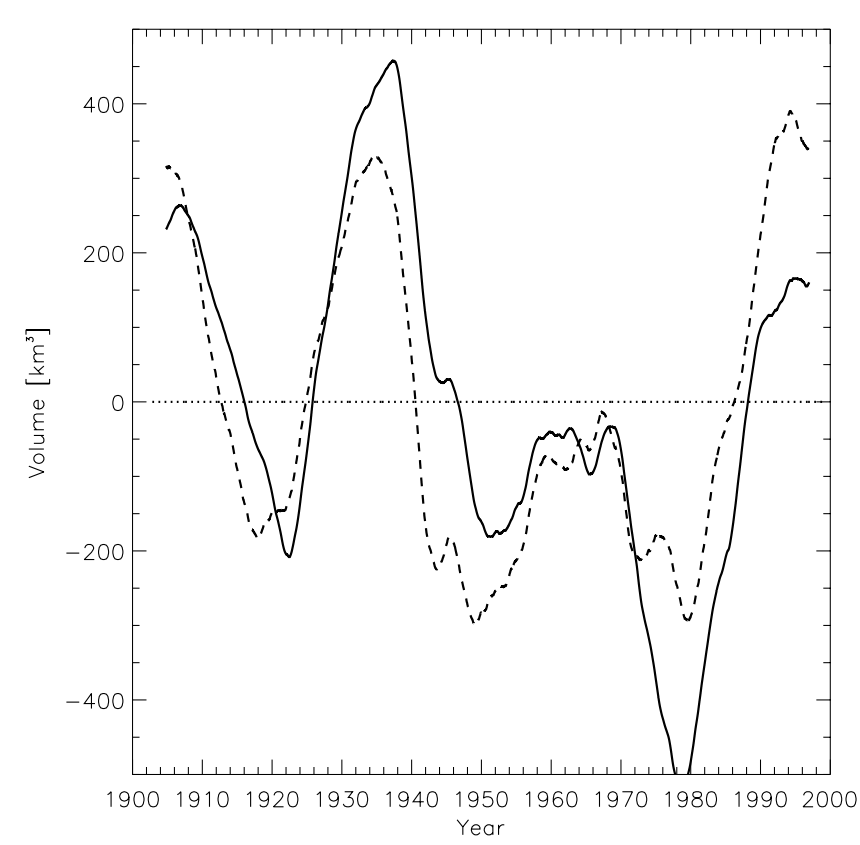

Figure 9. The 4-year running mean of accumulated river runoff and net precipitation anomaly (solid) and the 4-year running mean of freshwater storage anomaly (dashed). 
significantly at Stolpe Channel. Elken [1996] found 10,900 $\mathrm{m}^{3} \mathrm{~s}^{-1}$ for 1979-1994, whereas Kõuts and Omstedt [1993] calculated $33,200 \mathrm{~m}^{3} \mathrm{~s}^{-1}$ for $1970-1990$.

[40] In $\mathrm{H} 1$ the mean deepwater salt fluxes amount to 292 . $10^{3} \mathrm{~kg} \mathrm{~s}^{-1}$ in the Arkona Basin and to $341 \cdot 10^{3} \mathrm{~kg} \mathrm{~s}^{-1}$ at Stolpe Channel. The corresponding salt flux in the Arkona Basin calculated from observations is $307 \cdot 10^{3} \mathrm{~kg} \mathrm{~s}^{-1}$ [Gustafsson, 2001].

\section{Sensitivity Studies}

[41] With the help of sensitivity experiments we aim to explore the causes of the observed and simulated decadal variability of salinity or freshwater content in the Baltic Sea as shown, for example, in the Figures 8 and 9. Our approach is to remove successively the decadal variations in the forcing functions and to compare the results of the sensitivity experiments with the reference experiment $(\mathrm{H} 1)$ described in the previous section. The impact of the freshwater inflow, the wind, the air temperature (via the sea ice cover), and the sea level in Kattegat are studied.

[42] In the experiment F1 climatological monthly mean runoff and precipitation have been used to remove the interannual variability of the freshwater inflow. The mean seasonal cycle is calculated for the period 1902-1970 (Figure 4) to exclude the period when most of the dams in Sweden and Finland have been built.

[43] The influence of river regulation is addressed in another experiment (F2) for the period 1942-1998 with climatological monthly mean runoff and precipitation together with observed interannual variability. Again, the mean seasonal cycle is calculated for the period 1902-1970 with natural river discharge (Figure 4). For every individual year the difference between annual mean and climatological annual mean runoff has been added to the mean seasonal cycle. Consequently, the positive trend of the winter runoff since 1970 (Figure 3) has been removed but the interannual variability remained unchanged. Thus it is assumed that river regulation only redistributes the discharge from summer to winter without changing the annual mean runoff.

[44] Experiment A1 is based upon F1 (interannual variability of freshwater inflow removed). In addition, the daily SLP fields are high-pass filtered with a cutoff period of 4 years. Consequently, decadal variability of the surface wind fields is not considered.

[45] As saltwater inflows have never been observed during severe winters in the second part of the inflow season (January to April) [Fischer and Matthäus, 1996], one might speculate whether saltwater inflows are hampered by the rigid lid of sea ice especially during extremely severe winters when the entire surface area becomes ice covered. In a model study, Zhang and Leppäranta [1995] have shown that the water piling up with ice is decreased to one third, and that for severe ice conditions the current field magnitude dropped to $20 \%$ from the ice-free case. We investigated an extreme case when the air temperature of the calendar year 1941/1942 is cyclic repeated (experiment SI). During 1941/1942 the air temperatures over the Baltic Sea were the lowest of the last century and correspondingly the ice cover was at its maximum.

[46] Finally, an experiment has been performed with a high-pass-filtered sea level record in the Kattegat at the open boundary using a cutoff period of four years (SL). Because of the topographically induced flow resistance the Danish Straits act as low-pass filter for sea level oscillations in the Kattegat. A full response of the Baltic Sea mean sea level is attained for periods of about 1 year [Stigebrandt, 1984]. Consequently, the Baltic Sea volume is controlled by the Kattegat sea level for periods longer than one year. With experiment SL we address the question if the long-term sea level oscillations in the Kattegat affect also the salt content in the Baltic Sea. The experiments performed are summarized in Table 1.

\subsection{Impact of the Freshwater Inflow}

[47] During the 1920s and during the 1980s the freshwater inflows were larger than the climatological mean (Figure 3 and section 4.5). When the decadal variability of the freshwater inflow is omitted (F1), the variability of salinity or freshwater content is significantly reduced (Figures 10a and 11). However, there is still significant decadal variability left in the system. The still pronounced salinity minima during the 1930s and 1990s (Figure 11) indicate that other forcing mechanisms have also an impact on the decadal salt variations.

[48] A change of the seasonality of the freshwater inflow caused by river regulation has no significant impact on the decadal variability of the mean salinity. The response timescale of the system ( $\sim 35$ years) is much larger than a year. This is evident from the comparison between $\mathrm{H} 1$ and F2 (Figure 10c).

\subsection{Impact of the Sea Level Pressure}

[49] Associated to the low-frequency variability of the SLP fields is an anomalous west wind component in the Baltic Sea region during stagnation periods (Figure 2). This west wind anomaly causes a positive sea level difference between the Baltic proper and the Kattegat (Figure 12). As shown by Kauker and Meier [2003], the correlation between the reconstructed west wind representative for the Baltic Sea region and the sea level at Landsort is high for periods longer than 20 days. Similar results are found also for the correlation between observed zonal wind across the North Sea and the sea level in Kattegat [Gustafsson and Andersson, 2001] or the sea level at Stockholm [Andersson, 2002]. If the impact of the local wind over the Baltic is omitted, the variability of the sea level in the Baltic is only driven by external variations of the sea level in Kattegat [Samuelsson and Stigebrandt, 1996]. The local wind causes an additional piling up of water. For decadal oscillations, this impact of the local wind is illustrated in Figure 12. In general, the decadal variations of the reconstructed sea level at Landsort are in good agreement with observations (not shown). The sea level difference between F1 and A1 at Landsort is a measure for the impact of the low-frequency local wind because the prescribed sea level in Kattegat is the same in both experiments. Consequently, these variations are smaller than the observed variability at Landsort which includes both, the impact of the local wind and the impact of the externally driven sea level in Kattegat (Figure 12a). However, the variations are of the same magnitude than the difference between the observed sea level at Landsort and Smögen (Figure 12b). Of course, the correlation is not perfect as the sea level difference between Landsort and 

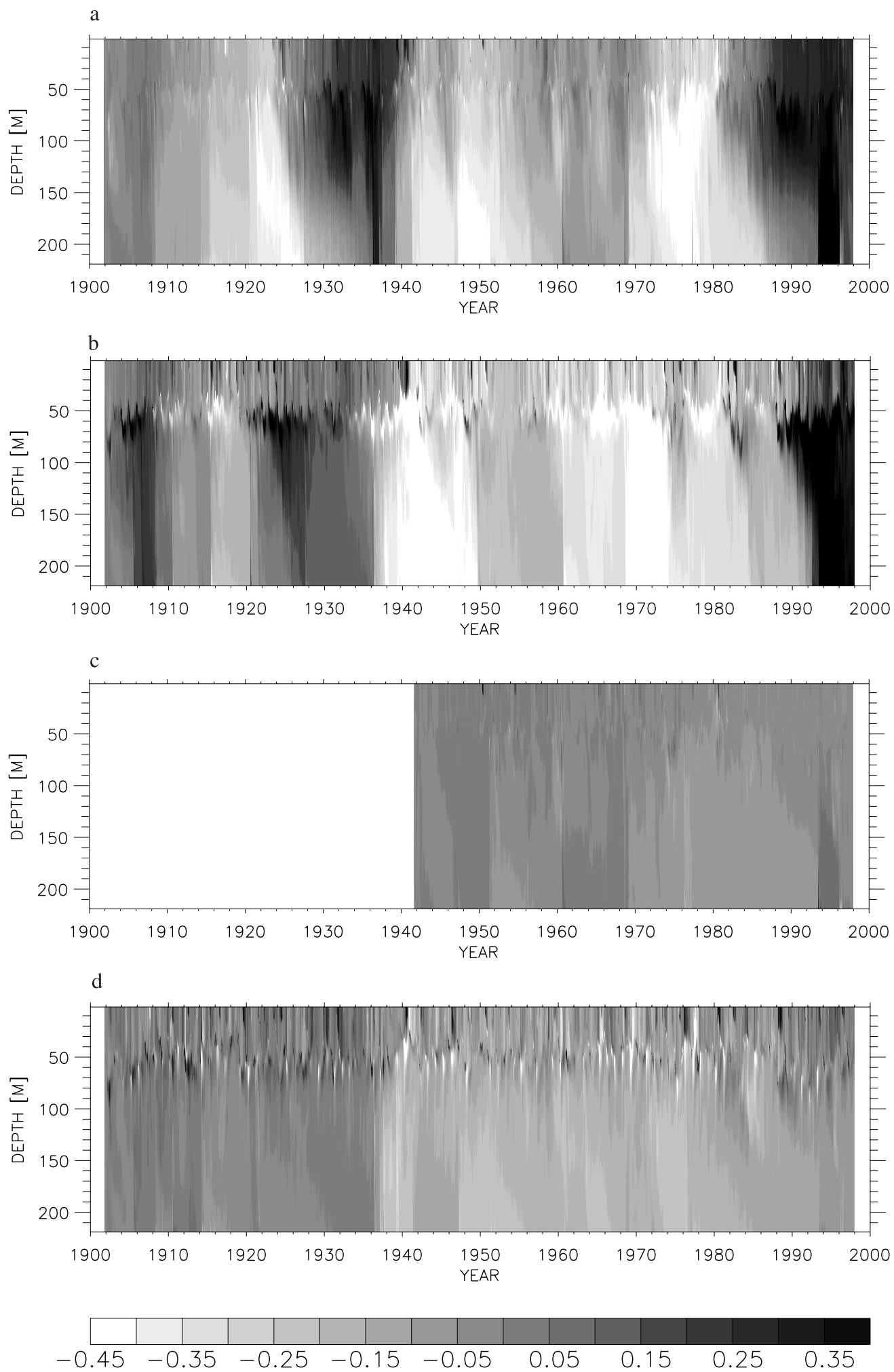

Figure 10. Salinity (in \%) as function of time and depth in the eastern Gotland Basin (BY15): (a) difference between the experiment with climatological monthly mean river runoff and precipitation of the period 1902-1970 (F1) and the standard experiment (H1), (b) difference between the experiment with climatological monthly mean river runoff and precipitation of the period 1902-1970 and with 4-year high-pass-filtered SLP and associated surface wind (A1) and F1, (c) difference between the sensitivity experiment with climatological monthly mean river runoff and precipitation of the period 1902-1970 and interannual variability for the period 1942-1998 (F2) and H1, and (d) difference between the sensitivity experiment with cyclic repeated air temperature from 1941/1942 (SI) and H1. See color version of this figure at back of this issue. 


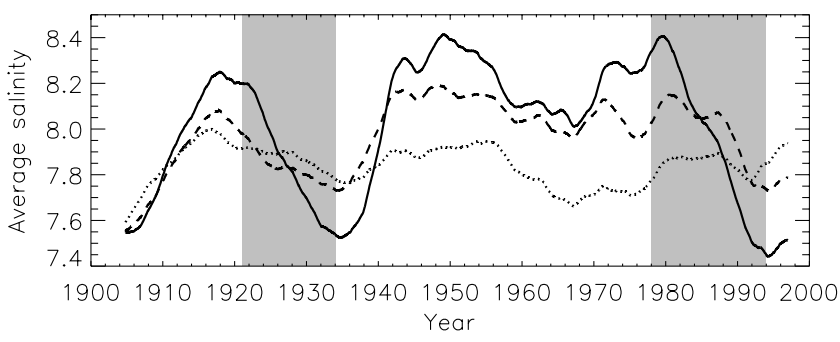

Figure 11. The 4-year running mean uncorrected salinity in the Baltic Sea without Kattegat (in \%o): H1 (solid), F1 (dashed), and A1 (dotted). The shaded periods are explained in Figure 3.

Smögen is only a coarse measure of the simulated slope between Landsort and the nodal line in the Danish Straits.

[50] The variability of salinity in the eastern Gotland Basin in A1 is further reduced compared to F1 (Figure 10b). We found the same behavior also for the average salinity of the Baltic Sea (Figure 11). Most of the simulated salinity variability is removed in A1. However, some decadal variability is still visible. Although the variability on timescales longer than four years is removed, the highfrequency forcing is not stationary. We estimated the probability density of the high-frequency variability for 20 years intervals (not shown). During these 20 year intervals the probability densities show small but significant variability. We attribute the remaining decadal variability to these fluctuations of the probability density of the highfrequency forcing.

[51] The stagnation periods caused by the freshwater inflow are shifted in time compared to the stagnation periods caused by the wind forcing (Figures 10a and 10b). The first stagnation period caused by the wind forcing starts 1921 and ends 1934 whereas the first stagnation period caused by the freshwater inflow lags by 7 years. The latter starts 1928 and ends 1941. The situation is different for the second stagnation period. Here, the freshwater inflow affects salinity since 1985, whereas the impact of the wind forcing is lagging by 4 years. The second stagnation period caused by the wind forcing starts 1989 . We have defined the exact start and end dates of the stagnation periods from the volume differences of high-saline water $(S \geq 9 \%)$ in the Baltic proper between the experiments $\mathrm{H} 1$ and $\mathrm{F} 1$ or between F1 and A1 (not shown).

\subsection{Impact of the Sea Ice}

[52] In SI, in every winter the entire Baltic Sea surface area is ice covered as in the cold winter 1941/1942. Especially at the end of the 1930 s, the inflow activity is hampered by the severe ice conditions (Figure 10d). During the period 1938-1993 the salinity in the Baltic deepwater in SI is significantly lower compared to H1. However, the salinity changes are much smaller than the changes due to the freshwater inflow variability (Figure 10a) or due to the SLP variability (Figure 10b).

[53] In an additional experiment, the interannual variability of all variables with direct impact on the sea ice, i.e., air temperature, specific humidity, and total cloudiness, has been removed from the reconstructed forcing. We found that the effect on salinity is even smaller than in SI (not shown).
Thus, in the present climate the impact of the sea ice cover on the average salinity in the Baltic Sea is negligible.

\subsection{Impact of the Sea Level in Kattegat}

[54] Analyzing the results of the sensitivity experiment SL we found that the impact of the decadal variability of the sea level at the open boundary in Kattegat on the average salinity in the Baltic Sea is negligible (not shown). The results of SL justify that the sea level in Kattegat has not been changed in F1 and A1. Externally driven sea level variations can be regarded as independent forcing on decadal timescales without impact on salinity.

\section{Decadal Variability of Volume and Salt Fluxes}

[55] In the Arkona Basin ( $\mathrm{C} 1$; see Figure 1) we found in the long-term mean a two-layer flow with outflow in the upper layer and inflow in the lower layer (not shown). A sill with a depth of about $60 \mathrm{~m}$ separates Bornholm Basin and the southern Gotland Basin at the western entrance of Stolpe Channel (C2; Figure 1). The high-saline water has to pass the channel on its way into the Gotland Deep (BY15). As the mean wind blows from a southwesterly direction, the transport in the surface layer has an eastward component (Figure 13). Below $48 \mathrm{~m}$ the deepwater flow is directed into the Gotland Basin whereas the compensating flow between 9 and $45 \mathrm{~m}$ depth is directed toward the west. At C3 the surface layer transport is directed northward with strong vertical gradients at the depths of the seasonal thermocline and the permanent halocline (Figure 13). Local minimum and maximum transports are found in $68 \mathrm{~m}$ and $97 \mathrm{~m}$ depth, respectively. The latter maximum within the halocline is caused by interleaving of saline water from Stolpe Channel
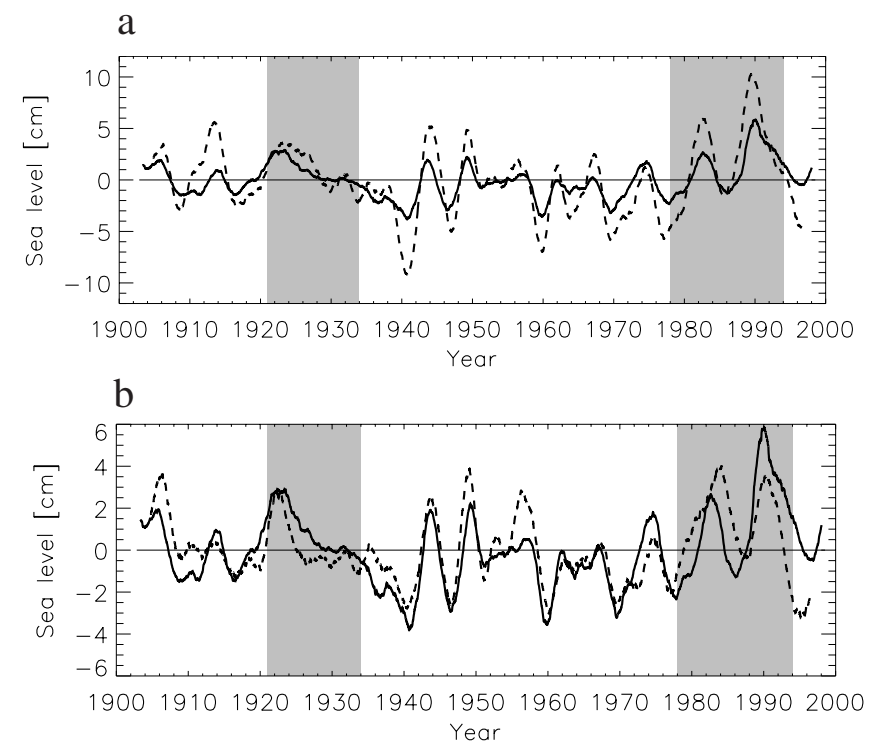

Figure 12. Sea level difference (in $\mathrm{cm}$ ) between $\mathrm{F} 1$ and A1 at Landsort (solid curves). High-frequency local oscillations are removed. In addition, (a) the 4-year running mean observed anomalies at Landsort or (b) the anomalies of the difference between Landsort and Smögen are shown (dashed curves). The shaded periods are explained in Figure 3. 


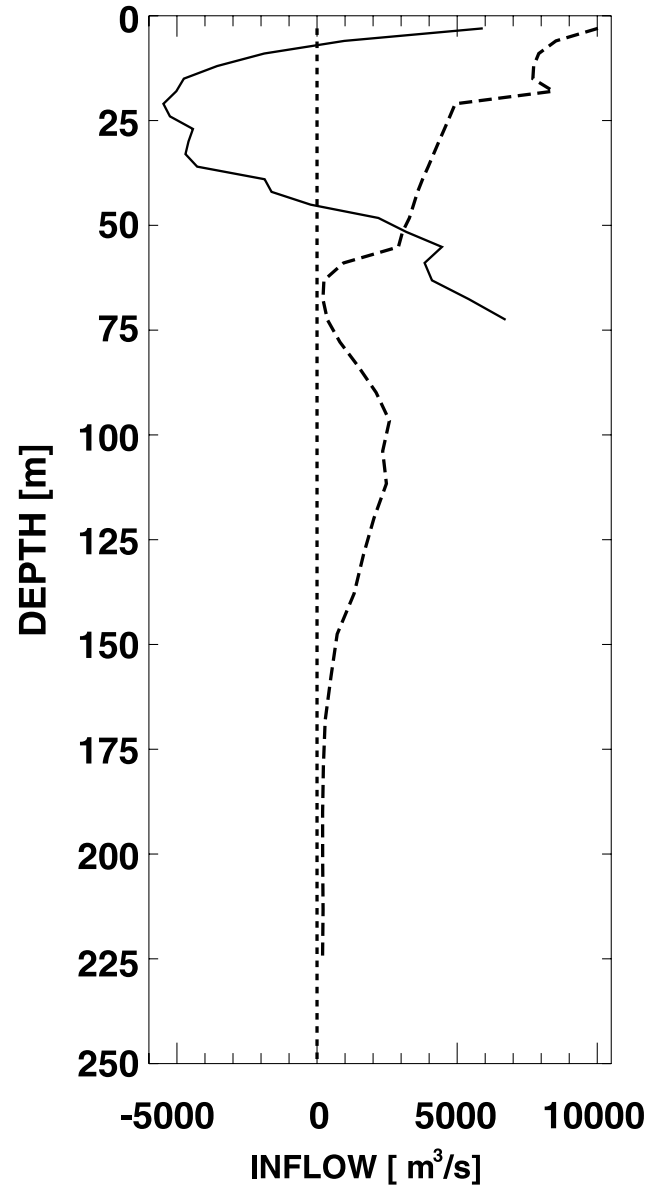

Figure 13. Total mean horizontally integrated transports (in $\mathrm{m}^{3} \mathrm{~s}^{-1}$ ) across a basin-wide section at Stolpe Channel (C2, solid line) and in the eastern Gotland Basin between Gotland and Estonia (C3, dashed line) for the period 19021998. At C2 (C3) eastward (northward) transports are counted positive. The positions of the sections are depicted in Figure 1.

which is not heavy enough to replace the bottom water at Gotland Deep. The vertical location of this maximum is in agreement with diagnostic model results by Elken [1996].

[56] The differences of the total mean transports at the two sections (C2 and $\mathrm{C} 3$ ) between $\mathrm{H} 1$ and $\mathrm{F} 1$ or between $\mathrm{F} 1$ and A1 are quite small (not shown). However, we found significant differences on decadal timescale (Figure 14). The two stagnation periods are clearly visible. During these periods the deepwater flows at $\mathrm{C} 2$ and $\mathrm{C} 3$ are reduced because of the increased freshwater inflow (Figures 14a and 14b). At $\mathrm{C} 2$ a wind induced, anomalous eastward transport component in the surface layer is always compensated by an anomalous westward transport in the deep layer below $20 \mathrm{~m}$ and vice versa (Figure 14c). Transport anomalies in the surface layer are highly correlated with wind speed anomalies (Figure 2). A westerly wind speed anomaly causes an Ekman transport anomaly toward the south. This Ekman transport produces a sea level rise on the southern side of the Stolpe Channel and a fall on the northern side. Furthermore, downwelling occurs on the southern side and upwelling on the northern side resulting in baroclinicity of the same sign at both sides of the channel. Consequently, jets are generated in the surface layer along both sides in wind direction and a return flow compensates this transport in the lower layer of the channel. This mechanism, first described by Krauss and Brügge [1991], is also dominant in our results on decadal timescale. The two stagnation periods are characterized by exceptionally strong westward anomalies of the deepwater flow through Stolpe Channel. At C3 the interleaving of high-saline water from the Bornholm Basin in about $100 \mathrm{~m}$ depth (Figure 13) is significantly reduced during the stagnation periods (Figure 14d). With progressing time the signal propagates into deeper layers because of the salinity decrease at Gotland Deep.

[57] Entrainment and the decadal variability of the deepwater volume flow increase significantly from $\mathrm{C} 1$ toward C2 (not shown). We found also a smaller increase of the pronounced decadal variations of the deepwater salt flux from $\mathrm{C} 1$ toward $\mathrm{C} 2$ (Figures 15 and 16). At both sections (C1 and $\mathrm{C} 2$ ) the decadal variability of the outflowing salt flux in the upper layer is much smaller showing the importance of mixing within the Baltic Sea. At C2 we found an additional, relatively small salt flow with large wind driven decadal variability close to the sea surface (Figure 16a; see Figure 13). During stagnation periods the deepwater salt transport into the Baltic proper is reduced but the surface salt transport is enhanced instead. The decadal variations of the sum of the surface and deepwater salt transports at $\mathrm{C} 2$ are about the same than the decadal variations of the deepwater salt transport at $\mathrm{C} 1$.

\section{Discussion}

[58] The RCO model has been validated earlier in hindcast simulations forced with observed atmospheric surface fields for the period 1980-1993 [e.g., Meier, 2001; Meier, 2002a, 2002b; Meier et al., 2003]. Therefore we have focused in our model validation on selected variables to detect artificial long-term trends caused by model biases or caused by shortcomings of the reconstruction procedure. No trend of the simulated Landsort sea level is found. The errors for the period 1902-1998 are of the same magnitude as found by Meier et al. [2003] for the shorter period 19801993.

[59] As the quasi steady state of the model is not consistent with the initial condition, the model drifts toward higher salinities during the first two decades of the century (Figure 11). The reason is unclear. Either mixing in the surface layer of the model is underestimated or restratification processes are overestimated. In the first case, underestimated extreme events of wind speed and unresolved processes generating turbulence, for example, Langmuir circulation [Axell, 2002], are likely candidates. In the second case, too strong mixing between the deepwater and the surface layer might contribute to an artificial restratification above the halocline.

[60] In general, horizontal volume and salt fluxes of the thermohaline circulation are simulated realistically during 1902-1998. However, in the Arkona Basin they are underestimated during the 1960s compared to geostrophic transports calculated by Gustafsson [2001] from observations for the period 1955-1995 (Figure 15). Consequently, the salinity in the eastern Gotland Basin is too low during this 
a

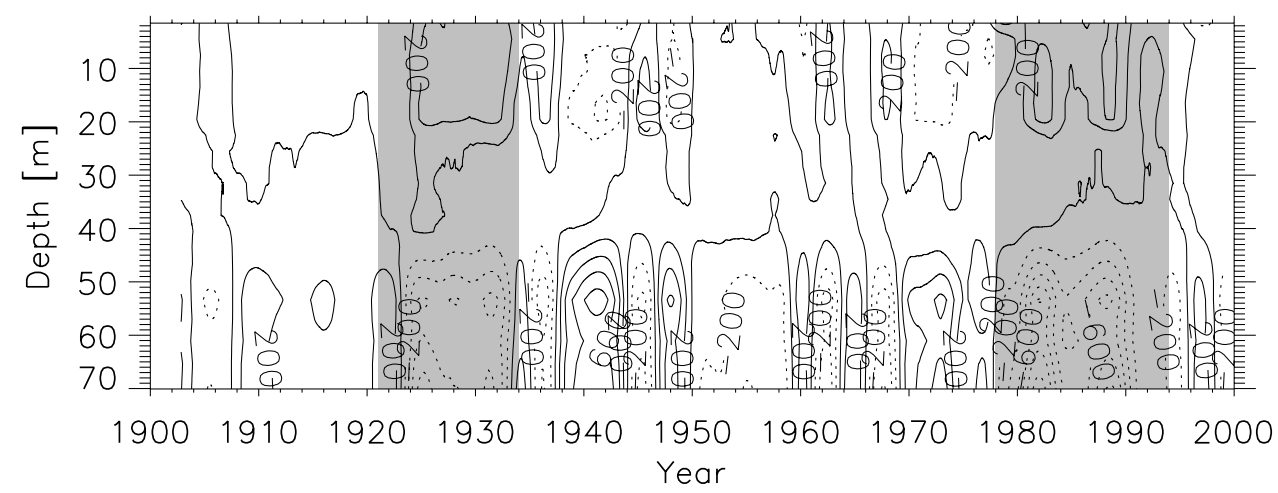

b

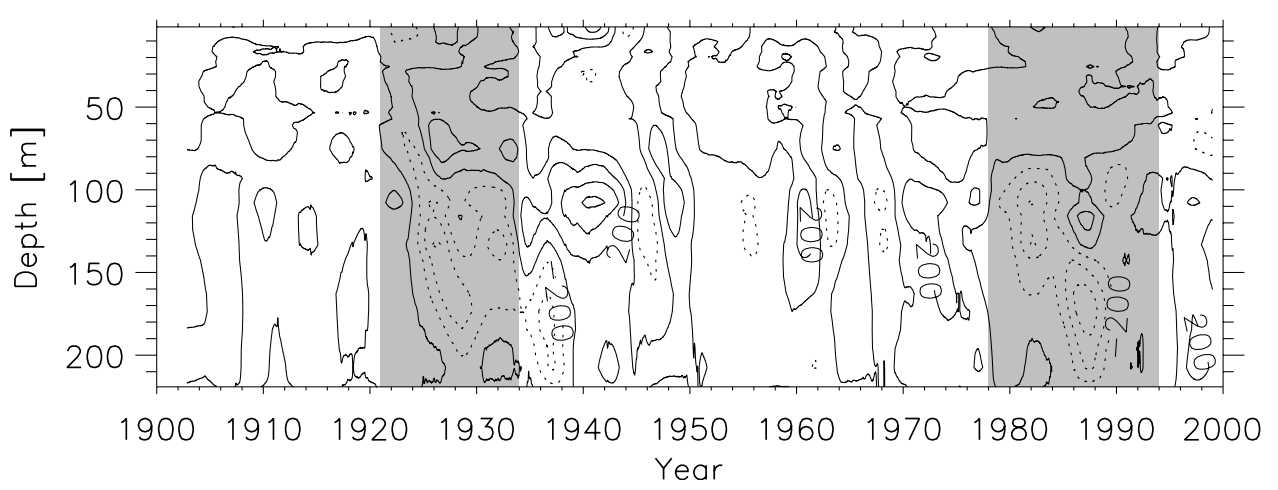

c

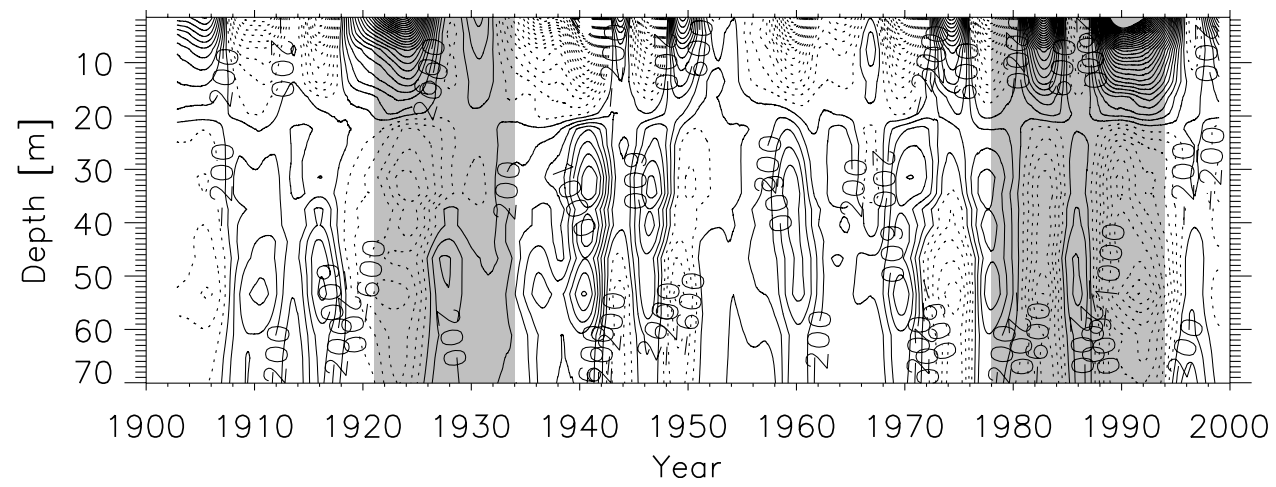

d

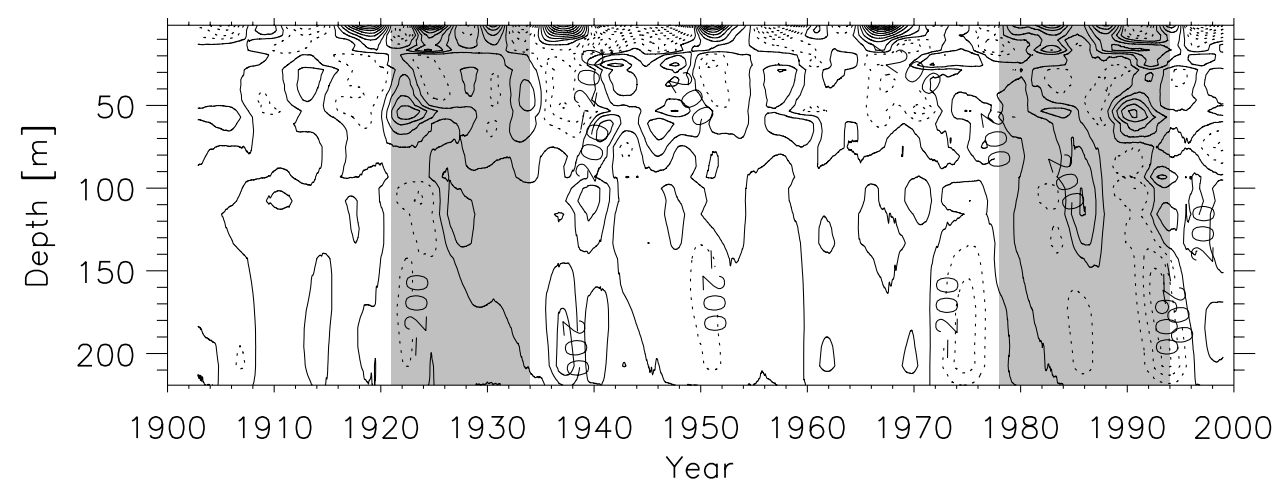

Figure 14. The 4-year running mean horizontally integrated transport anomalies (in $\mathrm{m}^{3} \mathrm{~s}^{-1}$ ) at (a) and (c) $\mathrm{C} 2$ and (b) and (d) C3: difference between H1 and F1 (Figures 14a and 14b) and between F1 and A1 (Figures 14c and 14d). At C2 (C3) eastward (northward) transport anomalies are counted positive (solid contours). Dotted contours are used for negative transport anomalies. Contour interval: $200 \mathrm{~m}^{3} \mathrm{~s}^{-1}$. The positions of the sections are depicted in Figure 1. The shaded periods are explained in Figure 3. 
a

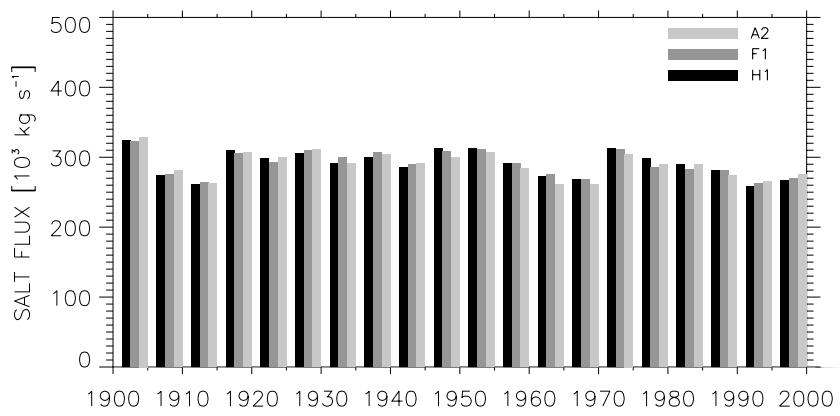

b

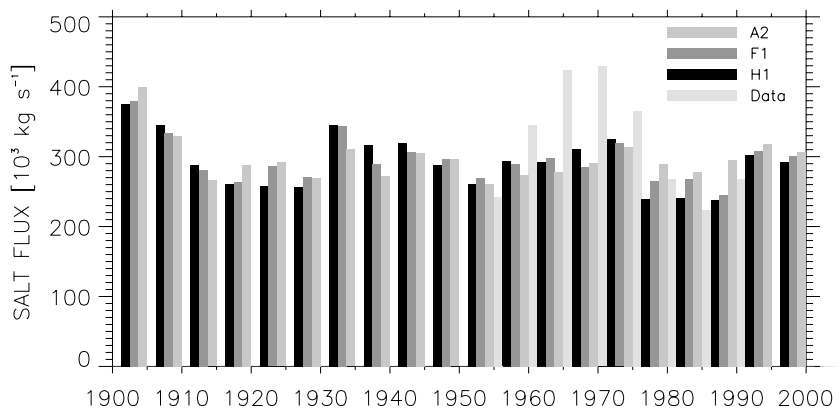

Figure 15. The 5-year averages of salt flux (in $10^{3} \mathrm{~kg} \mathrm{~s}^{-1}$ ) in the (a) upper and (b) lower layer at C1 (Figure 1). The upper (lower) layer salt flux is directed toward the west (east). Results calculated by Gustafsson [2001] from observations (denoted with "Data") are shown in addition.

period (Figure 7). We found much better results during the 1970s to 1990s compared to observations. The reason for this bias is unclear. The reconstructed SLP fields during the 1960s are as good as during other periods with better model performance [Kauker and Meier, 2003].

[61] Our results suggest that increased runoff and precipitation reduce the intensity of saltwater inflows but cannot explain the recent stagnation period (and the one during the 1920s) in the Baltic proper completely. Also changes of the large-scale SLP cause a further reduced salt transport into the Baltic Sea. Therefore the idea of a positive feedback mechanism between the freshwater content and the return flow of freshwater equivalents as discussed by Winsor et al. [2001] needs to be modified, at least on decadal timescale.

[62] Our model results agree well with the analysis of observed long time series by Schinke and Matthäus [1998]. Lass and Matthäus [1996] found an anomalous west wind component at the station Kap Arkona between August and October for seasons without major Baltic inflow compared to the corresponding seasons with major Baltic inflow during 1951-1990. They suggested that in years without major Baltic inflow the prevailing easterly winds of the one month lasting preconditioning phase prior to the main inflow event are reduced when the Baltic Sea is emptied. We have not investigated the impact of the high-frequency part of the reconstructed wind fields thoroughly. Indeed, the averaged Baltic Sea salinity (Figure 11) and the net salt transport into the Arkona Basin (not shown) reveal still some decadal variations if the variations caused by the freshwater inflow and the SLP with timescales larger than four years are removed. Therefore we assume that the remaining decadal variability is caused by high-frequency SLP fluctuations (see section 5.2). Our results only suggest that the Baltic Sea system might be quite sensitive to longterm changes of westerly winds. The existence of decadal variations of the reconstructed wind is supported by observations (Figures 2 and 12).

[63] Zorita and Laine [2000] found that stronger than normal westerly winds are related to lower than normal salinities in the upper and lower layers in all areas of the Baltic Sea. Their analysis of this link between the largescale atmospheric circulation and annual salinity reveals that roughly one half of the salinity variability is correlated to the meridional atmospheric pressure gradient over the North Atlantic, and thus to the strength of the westerly zonal winds. These results are confirmed by our model study. In the following, we provide a dynamical explanation for the apparent inconsistency discussed by Zorita and Laine [2000] that increased westerlies would cause more frequent
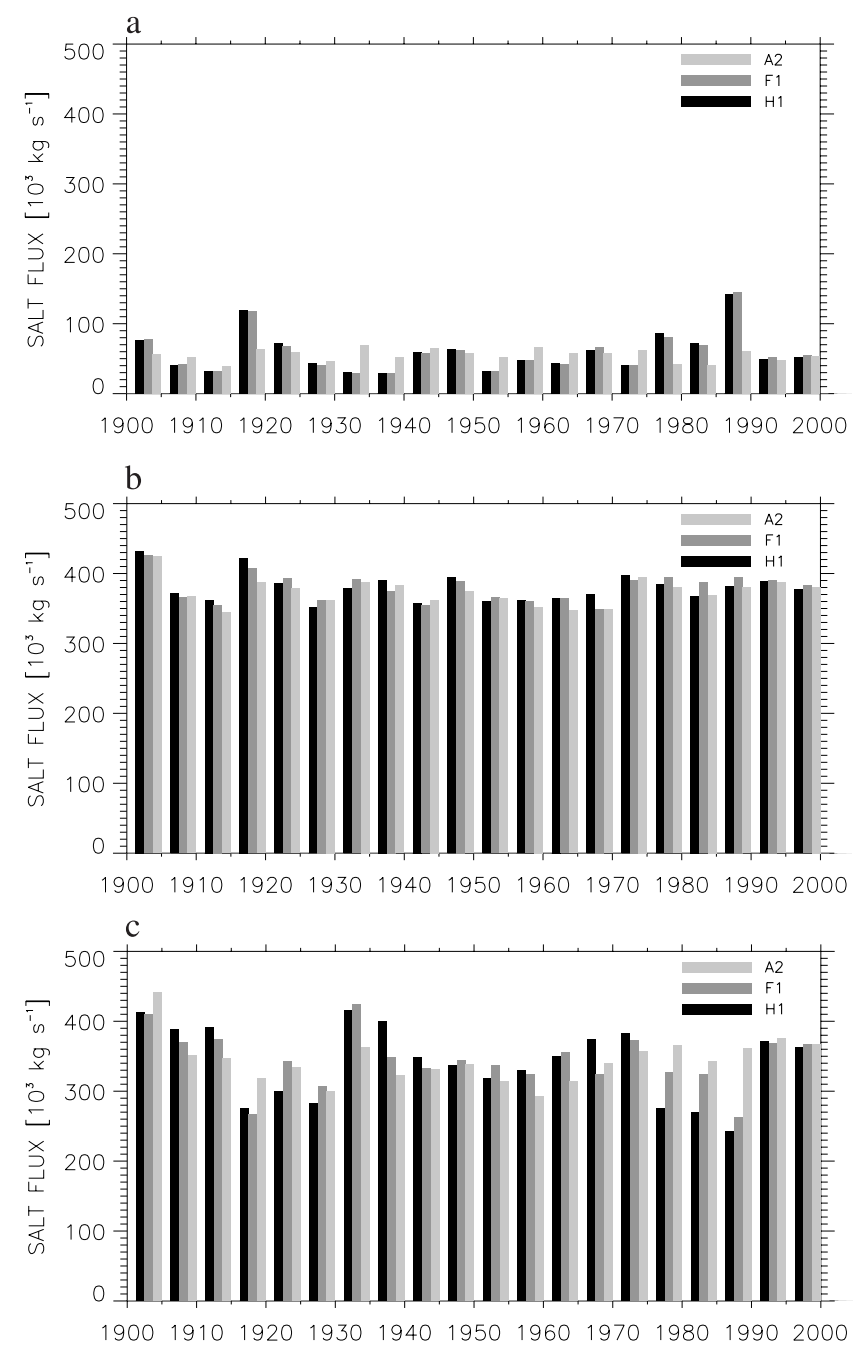

Figure 16. The 5-year averages of salt flux (in $10^{3} \mathrm{~kg} \mathrm{~s}^{-1}$ ) in the (a) surface, (b) medium, and (c) lower layer at $\mathrm{C} 2$ (Figure 1). The surface and lower-layer salt fluxes are directed toward the east, whereas the medium-layer salt flux is directed toward the west (Figure 13). 
and more intense major Baltic inflows. For periods longer than two weeks the amplitudes of the sea level oscillations increase monotonously toward the end of the Gulf of Bothnia and the end of the Gulf of Finland [Samuelsson and Stigebrandt, 1996]. Consequently, the system can be regarded for the decadal timescale as open like a bay or fjord where the nodal line is at the mouth. Anomalous strong west wind in the Baltic Sea region causes anomalous high piling up of water from the Danish Straits toward the Gulf of Bothnia and the Gulf of Finland. The flow of highsaline water through the Danish Straits into the Baltic proper is hampered because of the additional barotropic pressure gradient caused by anomalous high sea level in the Baltic Sea. The high sensitivity of the saltwater transport into the Baltic Sea on the mean sea level difference between the Bornholm Basin and the Kattegat has been noted already by Meier [1996]. Further investigations are still necessary to illuminate the processes involved.

[64] It should be mentioned that we investigated the sensitivity of a coarse resolution Baltic Sea model. The response might be different if mesoscale eddies are considered.

[65] The forcing functions of the Baltic Sea, the freshwater inflow (Figure 3) and the wind (Figure 2), are not independent forcing mechanisms but linked via the largescale atmospheric circulation on decadal timescale [Kauker and Meier, 2003]. This coincidence seems to be the explanation for the two remarkably pronounced stagnation periods of the last century. However, our model results show that the response of the average salinity on the freshwater inflow is lagging the response on the wind forcing in case of the first stagnation period. As the freshwater residence time is about 35 years (section 4.5), it take some years before the baroclinic pressure gradient has changed so much that the saltwater inflow into the Baltic Sea is obstructed. In case of the second stagnation period the situation is more complicated because the local west wind is not higher than normal during a certain decade but oscillates with a large amplitude and a period of about 7.8 years following the North Atlantic Oscillation [Hurrell, 1995; Jones et al., 1997]. Indeed, also during the second stagnation period the first signal visible in the Gotland Basin below the halocline is related to the wind impact (Figure 10b). However, the average salinity is first affected by the slower impact of the accumulated freshwater inflow.

\section{Conclusions}

[66] 1. The first 100-year hindcast simulations of the Baltic Sea using a 3-D coupled ice-ocean model have been presented. Because of technical limitations and because of a lack of atmospheric surface data for the Baltic Sea region, 100 -year simulations were not possible earlier. Baltic Sea climate of the period $1902-1998$ is simulated realistically with RCO. The variability on seasonal to decadal timescale is reproduced well mainly because the reconstructed atmospheric surface data and the other forcing fields have a good quality. Especially, decadal variations of the saltwater inflow frequency are captured by the model.

[67] 2. The simulated freshwater storage anomaly agrees well with observations. Thus our results confirm the earlier finding by Winsor et al. [2001] that the freshwater storage anomaly and the accumulated freshwater inflow are well correlated.

[68] 3. The total mean salinity of the Baltic Sea amounts to $7.36 \%$ (corrected model results). Decadal variations are of the order of 1\%. No long-term trend occurs during the century. Two exceptionally long stagnation periods are found.

[69] 4. Two main causes for the decadal variability of Baltic Sea salinity have been identified. About half of the decadal variability is related to the accumulated freshwater inflow. Another significant part of the decadal variability of salinity is caused by the low-frequency variability of the wind associated to the large-scale SLP over Scandinavia. During the stagnation periods anomalous strong westerly winds cause increased sea levels and reduced salt transports into the Baltic Sea. Additionally increased runoff and precipitation change the baroclinic pressure gradient on a slower timescale such that the salt transports are further reduced. The impact of the accumulated freshwater inflow lags the impact of the wind forcing by 7 years during the 1920s stagnation period and precedes it by 4 years during the 1980 s stagnation period.

[70] 5. If river regulation is assumed to change the discharge seasonality but not accumulated runoff, the impact of river regulations on the average salinity in the Baltic Sea is negligible.

[71] 6. A rigid ice lid covering the entire Baltic surface area has only a small impact on saltwater inflows in our model.

[72] 7. Decadal variability of the sea level in Kattegat has no impact on the average salinity. However, the highfrequency variability of the sea level in Kattegat is very important for the long-term behavior of average salinity in the system [e.g., Stigebrandt, 1983; Gustafsson, 2000] because variations with periods of about 20-30 days cause saltwater inflow events [Lass and Matthäus, 1996].

[73] Acknowledgments. This study is performed within the Swedish Regional Climate Modeling program (SWECLIM). SWECLIM is funded by the Foundation for Strategic Environmental Research (MISTRA) and by the Swedish Meteorological and Hydrological Institute (SMHI). The simulations have been performed on the Silicon Graphics Origin 3800 at the Swedish National Supercomputer Centre in Linköping, Sweden. Special thanks are given to Barry Broman (SMHI) for providing tide gauge data, to Bengt Carlsson (SMHI), Phil Graham (SMHI), and Jercy Cyberski (University of Gdansk, Poland) for providing river runoff data, and to Bo Gustafsson (Göteborg University, Sweden) for providing volume and salt flow data from the Arkona Basin. Temperature and salinity profiles of the Marine Data Centre of the International Council for the Exploration of the Sea (ICES) and ice area data from the Global Digital Sea Ice Data Bank of the USA National Ice Center have been used. Very helpful information concerning the quality of Baltic Sea ice observations in general and the maximum ice extent data from the Finnish Institute of Marine Research (FIMR) in special are provided by Jouko Launiainen (FIMR). We would like to acknowledge the reviewers for their constructive comments.

\section{References}

Andersson, H. C., Influence of long-term regional and large-scale atmospheric circulation on the Baltic Sea level, Tellus, Ser. A, 54, 76-88, 2002 .

Axell, L. B., Wind-driven internal waves and Langmuir circulations in a numerical ocean model of the southern Baltic Sea, J. Geophys. Res., 107(C11), 3204, doi:10.1029/2001JC000922, 2002.

Bergström, S., and B. Carlsson, River runoff to the Baltic Sea: 1950-1990, Ambio, 23, 280-287, 1994.

Bumke, K., U. Karger, L. Hasse, and K. Niekamp, Evaporation over the Baltic Sea as an example of a semi-enclosed sea, Contrib. Atmos. Phys., 71, 249-261, 1998 . 
Cyberski, J., and A. Wroblewski, Riverine water inflows and the Baltic Sea water volume 1901-1990, Hydrol. Earth Syst. Sci., 4, 1-11, 2000.

D'Asaro, E. A., The energy flux from the wind to near-inertial motions in the surface mixed layer, J. Phys. Oceanogr., 15, 1043-1059, 1985.

Ekman, M., A consistent map of the postglacial uplift of Fennoscandia, Terra Nova, 8, 158-165, 1996.

Ekman, M., Climate changes detected through the world's longest sea level series, Global Planet. Change, 21, 215-224, 1999.

Ekman, M., and J. Mäkinen, Mean sea surface topography in the Baltic Sea and its transition area to the North Sea: A geodetic solution and comparison with oceanographic models, J. Geophys. Res., 101, 11,993-11,999, 1996.

Elken, J., Deep water overflow, circulation and vertical exchange in the Baltic Proper, Rep. Ser. 6, 91 pp., Estonian Mar. Inst., Tallinn, Estonia, 1996.

Fischer, H., and W. Matthäus, The importance of the Drogden Sill in the Sound for major Baltic inflows, J. Mar. Syst., 9, 137-157, 1996.

Graham, P. L., Modeling runoff to the Baltic Sea, Ambio, 27, 328-334, 1999.

Granqvist, G., Översikt av isarna vintern 1926-27, Havsforskningsinst. Skrift 55, Finn. Inst. of Mar. Res., Helsinki, 1928.

Gustafsson, B. G., Time-dependent modeling of the Baltic entrance area 2. Water and salt exchange of the Baltic Sea, Estuaries, 2, 253-266, 2000.

Gustafsson, B. G., Quantification of water, salt, oxygen and nutrient exchange of the Baltic Sea from observations in the Arkona Basin, Cont. Shelf Res., 21, 1485-1500, 2001.

Gustafsson, B. G., and H. C. Andersson, Modeling the exchange of the Baltic Sea from the meridional atmospheric pressure difference across the North Sea, J. Geophys. Res., 106, 19,731-19,744, 2001.

Hibler, W. D., A dynamic thermodynamic sea ice model, J. Phys. Oceanogr., 9, 817-846, 1979.

Hurrell, J. W., Decadal trends in the North Atlantic Oscillation: Regional temperatures and precipitation, Science, 269, 676-679, 1995.

Janssen, F., Statistische Analyse mehrjähriger Variabilität der Hydrographie in Nord- und Ostsee, Ph.D. thesis, 150 pp., Univ. of Hamburg, Inst. of Mar. Res., Hamburg, Germany, 2002.

Janssen, F., C. Schrum, and J. Backhaus, A climatological dataset of temperature and salinity for the North Sea and the Baltic Sea, Dtsch. Hydrogr. Z., 9, suppl., 245 pp., 1999.

Jones, P. D., T. Jonsson, and D. Wheeler, Extension to the North Atlantic Oscillation using early instrumental pressure observations from Gibraltar and south-west Iceland, Int. J. Climatol., 17, 1433-1450, 1997.

Jurva, R., Über den allgemeinen Verlauf des Eiswinters in den Meeren Finnlands und über die Schwankungen der grössten Vereisung, Sitzungsber. 1941, Finn. Akad. der Wissenschaften, Helsinki, 1944.

Kauker, F., and H. E. M. Meier, Modeling decadal variability of the Baltic Sea: 1. Reconstructing atmospheric surface data for the period 1902 1998, J. Geophys. Res., 108(C8), 3267, doi:10.1029/2003JC001797, 2003.

Kõuts, T., and A. Omstedt, Deep water exchange in the Baltic Proper, Tellus, Ser. A, 45, 311-324, 1993.

Krauss, W., and B. Brügge, Wind-produced water exchange between the deep basins of the Baltic Sea, J. Phys. Oceanogr., 21, 373-384, 1991.

Lass, H.-U., and W. Matthäus, On temporal wind variations forcing salt water inflows into the Baltic Sea, Tellus, Ser. A, 48, 663-671, 1996.

Liljebladh, B., and A. Stigebrandt, Observations of the deepwater flow into the Baltic Sea, J. Geophys. Res., 101, 8895-8911, 1996.

Matthäus, W., and H. Franck, Characteristics of major Baltic inflows-A statistical analysis, Cont. Shelf Res., 12, 1375-1400, 1992.

Matthäus, W., and H. Schinke, The influence of river runoff on deep water conditions of the Baltic Sea, Hydrobiologia, 393, 1-10, 1999.

Meier, H. E. M., A regional model of the western Baltic sea with open boundary conditions and data assimilation (in German), Ber. Inst. Meereskunde 284, 117 pp., Inst. of Mar. Res., Kiel, Germany, 1996.

Meier, H. E. M., On the parameterization of mixing in three-dimensional Baltic Sea models, J. Geophys. Res., 106, 30,997-31,016, 2001.

Meier, H. E. M., Regional ocean climate simulations with a 3D ice-ocean model for the Baltic Sea. part 1: Model experiments and results for temperature and salinity, Clim. Dyn., 19, 237-253, 2002a.

Meier, H. E. M., Regional ocean climate simulations with a 3D ice-ocean model for the Baltic Sea. part 2: Results for sea ice, Clim. Dyn., 19, 255 266, $2002 b$.
Meier, H. E. M., and R. Döscher, Simulated water and heat cycles of the Baltic Sea using a 3D coupled atmosphere-ice-ocean model, Boreal Environ. Res., 7, 327-334, 2002.

Meier, H. E. M., R. Döscher, A. C. Coward, J. Nycander, and K. Döös, $\mathrm{RCO}$ - Rossby Centre regional Ocean climate model: Model description (version 1.0) and first results from the hindcast period 1992/93, Rep. Oceanogr. 26, Swed. Meteorol. Hydrol. Inst., Norrköping, Sweden, 102 pp., 1999.

Meier, H. E. M., R. Döscher, and T. Faxén, A multiprocessor coupled iceocean model for the Baltic Sea: Application to salt inflow, J. Geophys. Res., 108(C8), 3273, doi:10.1029/2000JC000521, 2003.

Mikulski, Z., Inflow from drainage basin, in Water Balance of the Baltic Sea-Baltic Sea Environment Proceedings, vol. 16, pp. 24-34, Baltic Mar. Environ. Prot. Comm., Helsinki, Finland, 1986.

Neumann, G., Eigenschwingungen der Ostsee, Arch, Dtsch. Seewarte Marineobs., 61, 1-59, 1941.

Omstedt, A., and L. Axell, Modeling the seasonal, interannual and longterm variations of salinity and temperature in the Baltic proper, Tellus, Ser. $A, 50,637-652,1998$.

Omstedt, A., and L. Nyberg, Response of Baltic Sea ice to seasonal, interannual forcing and climate change, Tellus, Ser. A, 48, 644-662, 1996.

Omstedt, A., L. Meuller, and L. Nyberg, Interannual, seasonal and regional variations of precipitation and evaporation over the Baltic Sea, Ambio, 26, 484-492, 1997.

Palosuo, E., A treatise on severe ice conditions in the central Baltic, Havsforskningsinst. Skrift 156, Finn. Inst. of Mar. Res., Helsinki, 1953.

Rodhe, J., and P. Winsor, On the influence of the freshwater supply on the Baltic Sea mean salinity, Tellus, Ser. A, 54, 175-186, 2002.

Rutgersson, A., A. Omstedt, and J. Räisänen, Net precipitation over the Baltic Sea during present and future climate conditions, Clim. Res., 22, 27-39, 2002.

Samuelsson, M., and A. Stigebrandt, Main characteristics of the long-term sea level variability in the Baltic Sea, Tellus, Ser. A, 48, 672-683, 1996.

Schinke, H., and W. Matthäus, On the causes of major Baltic inflows-An analysis of long time series, Cont. Shelf Res., 18, 67-97, 1998.

Schrum, C., F. Janssen, and U. Hübner, Recent climate modelling in North Sea and Baltic Sea. part A: Model description and validation, Ber. Zentrum Meeres- Klimaforschung 37, 60 pp., Zentrum für Meeres- und Klimaforschung, Hamburg, Germany, 2000.

Seifert, T., and B. Kayser, A high resolution spherical grid topography of the Baltic Sea, Meereswiss. Ber., Warnemünde, 9, 73-88, 1995.

Seinä, A., and E. Palosuo, The classification of the maximum annual extent of ice cover in the Baltic Sea 1720-1992, Meri 20, Finn. Inst. of Mar. Res., Helsinki, 1993.

Stevens, D. P., On open boundary conditions for three dimensional primitive equation ocean circulation models, Geophys. Astrophys. Fluid Dyn., $51,103-133,1990$.

Stigebrandt, A., A model for the exchange of water and salt between the Baltic and the Skagerrak, J. Phys. Oceanogr., 13, 411-427, 1983.

Stigebrandt, A., Analysis of an 89-year-long sea level record from the Kattegat with special reference to the barotropically driven water exchange between the Baltic and the sea, Tellus, Ser. A, 36, 401-408, 1984.

Webb, D. J., A. C. Coward, B. A. de Cuevas, and C. S. Gwilliam, A multiprocessor ocean circulation model using message passing, J. Atmos. Oceanic Technol., 14, 175-183, 1997.

Winsor, P., J. Rodhe, and A. Omstedt, Baltic Sea ocean climate: An analysis of $100 \mathrm{yr}$ of hydrographic data with focus on the freshwater budget, Clim. Res., 18, 5-15, 2001.

Zhang, Z.-H., and M. Leppäranta, Modeling the influence of ice on sea level variations in the Baltic Sea, Geophysica, 31, 31-45, 1995.

Zorita, E., and A. Laine, Dependence of salinity and oxygen concentrations in the Baltic Sea on large-scale atmospheric circulation, Clim. Res., 14, $25-41,2000$.

F. Kauker, Alfred Wegener Institute for Polar and Marine Research, Bussestr. 24, P.O. Box 120161, D-27515 Bremerhaven, Germany. (fkauker@awi-bremerhaven.de)

H. E. M. Meier, Swedish Meteorological and Hydrological Institute, Rossby Centre, SE-60176 Norrköping, Sweden. (markus.meier@smhi.se) 


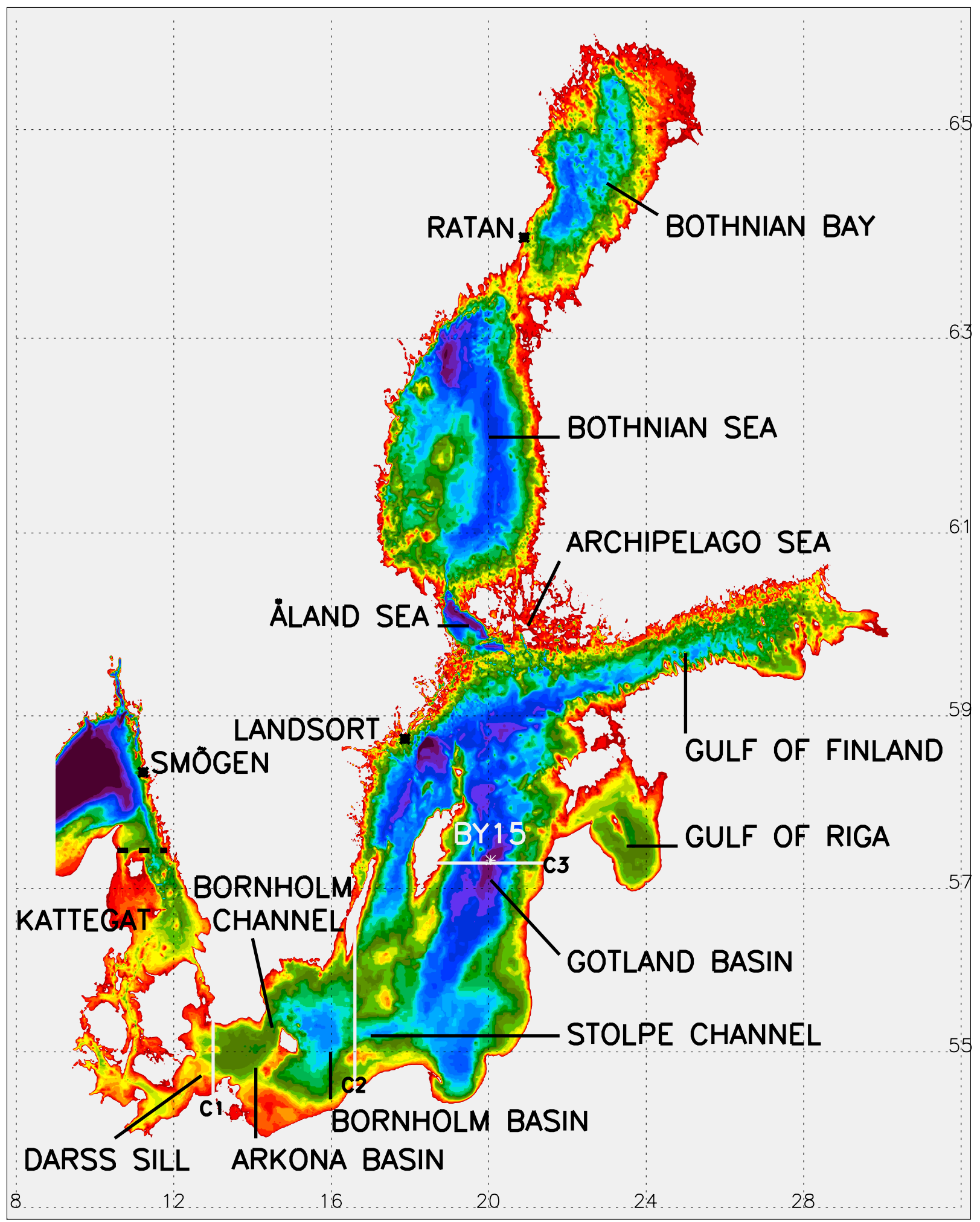

DEPTH [M]

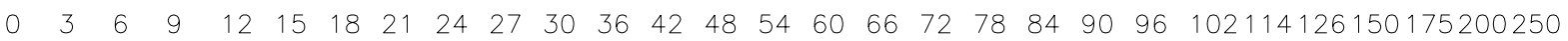

Figure 1. Bottom topography of the Baltic Sea including Kattegat and Skagerrak (data from Seifert and Kayser [1995]). The domain of the Rossby Centre Ocean model (RCO) is limited with open boundaries in the northern Kattegat (dashed line). Selected monitoring positions and cross sections (C1 to C3, white lines) are depicted additionally. 

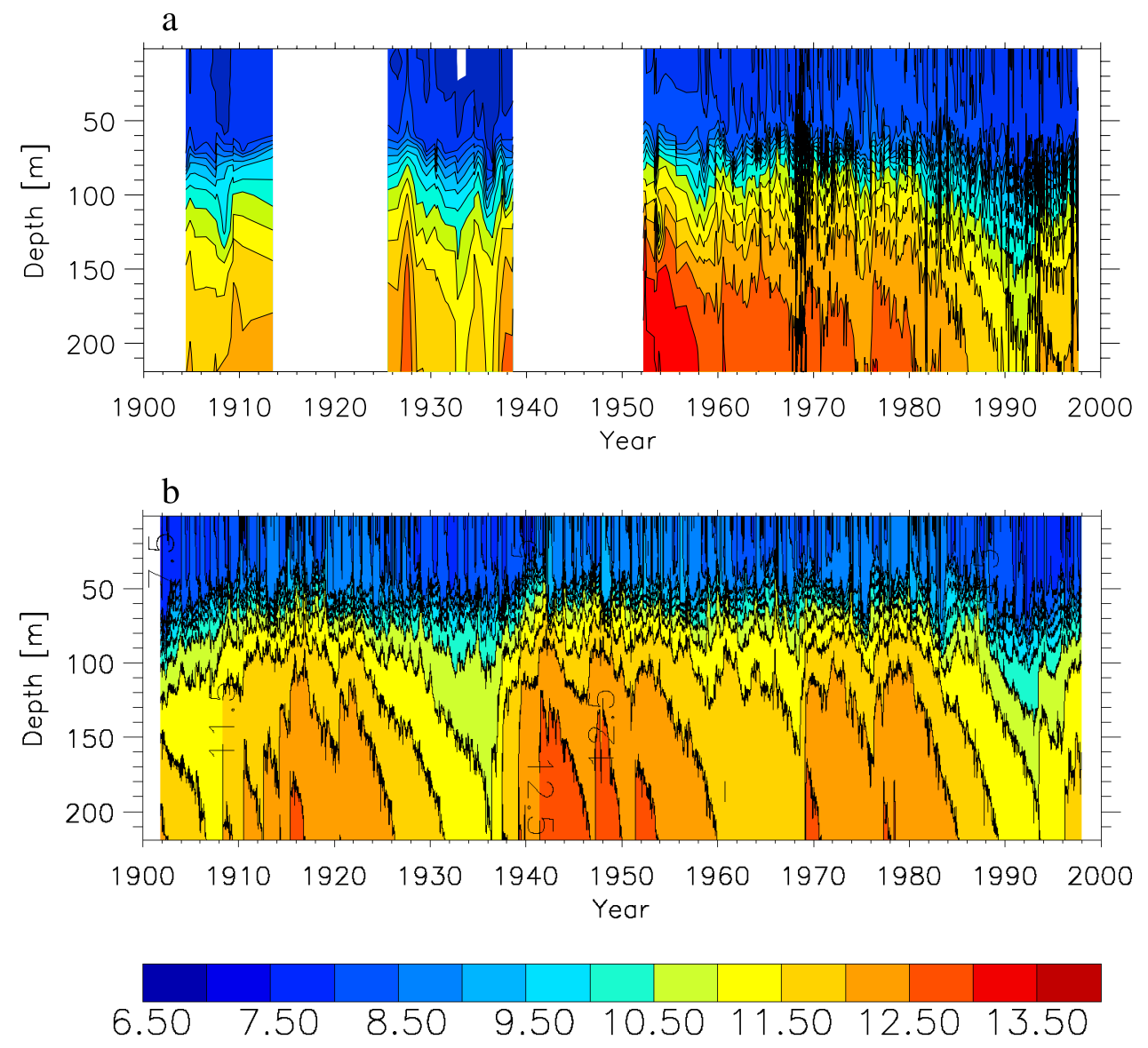

Figure 7. Salinity (in \%o) as function of time and depth in the eastern Gotland Basin (BY15): (a) observations and (b) model results. Observations are not available for periods covering the world wars. 

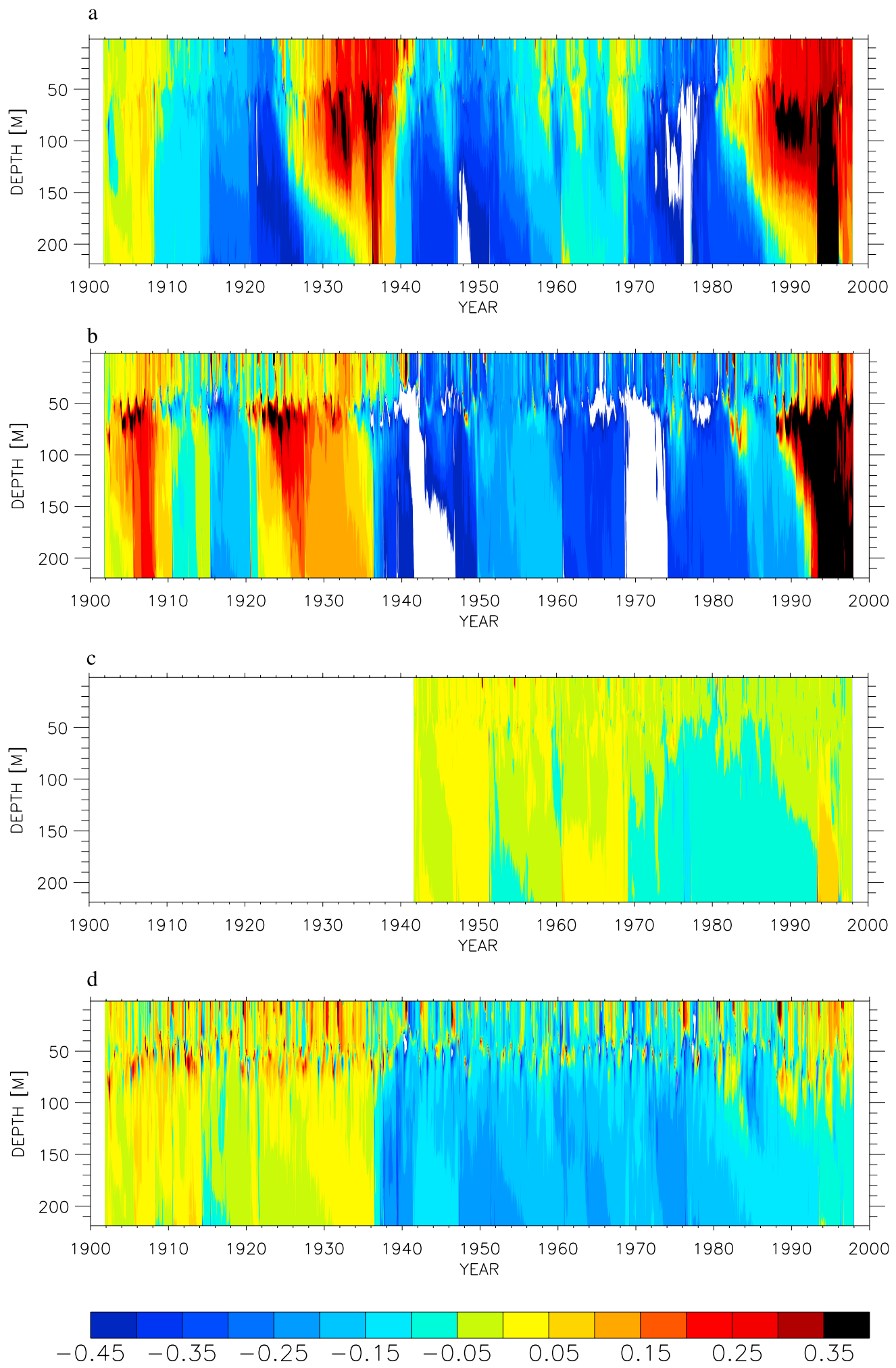

Figure 10. Salinity (in \%) as function of time and depth in the eastern Gotland Basin (BY15): (a) difference between the experiment with climatological monthly mean river runoff and precipitation of the period 1902-1970 (F1) and the standard experiment (H1), (b) difference between the experiment with climatological monthly mean river runoff and precipitation of the period 1902-1970 and with 4-year high-pass-filtered SLP and associated surface wind (A1) and F1, (c) difference between the sensitivity experiment with climatological monthly mean river runoff and precipitation of the period 1902-1970 and interannual variability for the period 1942-1998 (F2) and H1, and (d) difference between the sensitivity experiment with cyclic repeated air temperature from 1941/1942 (SI) and H1. 